\title{
Environmental degradation of claystones
}

\author{
J. A. PINEDA*, E. E. ALONSO† and E. ROMERO†
}

\begin{abstract}
The paper presents the results of a comprehensive experimental programme carried out to study the effects of relative humidity cycling on the degradation of argillaceous rocks. Lilla claystone, a lowporosity Tertiary rock, was used for this purpose. Four aspects were analysed: $(a)$ the influence of the number of relative humidity cycles; $(b)$ the amplitude of relative humidity cycles; $(c)$ the stress level; and $(d)$ the effects of using liquid water or vapour during wetting paths. The application of relative humidity cycles induced a progressive degradation of the rock in terms of accumulative irreversible volumetric swelling, irreversible reduction in rock stiffness, and tensile strength. The irreversible expansion increased with the amplitude of the relative humidity change. However, it reduced with increase of the confining pressure. This irreversible behaviour accelerated when liquid water was used during the wetting paths. Microstructural analysis has shown that the degradation pattern of Lilla claystone was associated mainly with fissuring, as a consequence of non-uniform deformations of the clayey matrix. This phenomenon leads to the opening of fissures at the weaker interfaces of the clayey matrix with detrital, non-active minerals. A damage law derived in terms of the accumulated volumetric irreversible strain has been proposed to represent the progressive loss in volumetric and shear stiffness as well as the tensile strength.
\end{abstract}

KEYWORDS: clays; laboratory tests; rocks/rock mechanics; shear strength; stiffness; suction

\section{INTRODUCTION}

Argillaceous rocks are common in many countries, and are frequently present in civil engineering projects. A recurrent observation in these materials is their evolutive nature, which emerges mainly when they are excavated and exposed to weathering processes (Gens, 2010). Marls, shales, claystones, mudstones, siltstones and very stiff clays are examples of materials that undergo these changes (e.g. Bjerrum, 1967; Chandler, 1969, 1972; Botts, 1986; Cafaro \& Cotecchia, 2001; Alonso et al., 2010). Despite intrinsic geological differences, the argillaceous rocks show two similar characteristics: $(a)$ a behaviour intermediate between rock and soil; and $(b)$ a high 'degradation' potential ability to change their mechanical properties, transforming the clayey rock into a soil. This transition is especially relevant when the rock is exposed to unloading and environmental effects (Cripps \& Taylor, 1981; Alonso et al., 2010).

Rock degradation has commonly been related to increase in water content. This change is the consequence of weathering processes, and in particular the cyclic variations in relative humidity. For tunnels, chemically or thermally induced disturbances during excavation and support operations are modest or negligible if compared with hydromechanical disturbances (e.g. Charpentier et al., 2003; Rejeb \& Cabrera, 2006). Relative humidity exhibits cyclic variations. Maximum fluctuations depend on site conditions, although values around $50 \%<\Delta \mathrm{RH}<75 \%$ are quite common during a typical annual variation (e.g. Olivier, 1979; Rejeb \& Cabrera, 2006; Berdugo, 2007). Such cyclic behaviour is accompanied by irreversible volume changes. Case histories have

Manuscript received 10 April 2013; revised manuscript accepted 27 August 2013. Published online ahead of print 27 November 2013.

Discussion on this paper closes on 1 June 2014, for further details see p. ii.

$*$ ARC Centre of Excellence for Geotechnical Science and Engineering, University of Newcastle Australia, Newcastle, NSW, Australia (formerly at Universitat Politècnica de Catalunya).

$\dagger$ Department of Geotechnical Engineering and Geosciences, Universitat Politècnica de Catalunya, Barcelona, Spain. been reported by many authors during recent decades (Bjerrum, 1967; Van Eeckhout, 1976; Olivier, 1979; Botts, 1986; Picarelli \& Urciuoli, 1993; Vaughan, 1997; Wong, 1998; Cafaro \& Cotecchia, 2001; Pejón \& Zuquette, 2002; Alonso \& Alcoverro, 2004; Valès et al., 2004; Marques et al., 2005; Rejeb \& Cabrera, 2006; Picarelli \& Di Maio, 2010; Youn \& Tonon, 2010; Alonso et al., 2010; Cardoso et al., 2012; Pineda \& Romero, 2013).

In this paper, rock degradation refers to the irreversible changes in mechanical properties that occur as a result of weathering processes. Thus rock degradation can be evaluated - from a macroscopic viewpoint - in terms of the loss in strength and stiffness, in terms of irreversible volume changes (swelling), and in terms of loss of mass continuity (fissuring) (Alonso \& Alcoverro, 2004). At the microscopic level, degradation may be evaluated in terms of modifications in the structural arrangement of rock constituents, and in changes of composition and pore-size distribution.

The primary mechanisms leading to rock degradation are not well understood. Cripps \& Taylor (1981) reviewed the properties of British mudrocks, and discussed the weathering mechanism. In recent investigations, Montes et al. (2004), Fabre \& Pellet (2006) and Gasc-Barbier \& Tessier (2007) have remarked on the important role played by the clayey matrix during degradation of argillaceous rocks. However, a solid link between the response at the macro level and the evolution of microstructure is not well established.

This paper presents the results of an experimental investigation aimed at evaluating the influence of relative humidity cycling on the degradation of Lilla claystone, a low-porosity rock from north-east Spain. The main factors influencing rock degradation have been studied, with particular emphasis placed on the consequences of relative humidity cycling at the micro scale. A framework of behaviour, based on experimental evidence, is described, and a novel degradation law is proposed.

\section{MATERIAL, EQUIPMENT AND PROCEDURES}

Claystones are often found in the Iberian Peninsula. The authors had the opportunity to analyse some of these forma- 
tions in connection with civil engineering projects (dam foundations, tunnels and excavations). The claystones' mineral constituents and basic geotechnical indices are given in Table 1. Also included in the table are two formations (Opalinus clay in Switzerland, and the Callovo-Oxfordian mudstone in France) that have been investigated in connection with nuclear waste disposal research. Despite differences in geological origin and age, the materials listed in Table 1 exhibit significant similarities when their porosity, plasticity and unconfined compression strength are compared. In general terms, the materials in Table 1 have a dominant low-plasticity clayey matrix (often in excess of $50 \%$ ), and significant proportions of carbonates and quartz. The Iberian formations listed are known for their high degradation potential when they are first excavated and exposed to atmospheric action.

The rock investigated here is Lilla claystone, a sulfatebearing rock of Tertiary age from the Lower Ebro basin in Tarragona Province, Catalunya. Lilla claystone has two main constituents: $(a)$ the rock matrix, which includes phyllosilicates, dolomite and quartz; and $(b)$ smaller but variable proportions of anhydrite and gypsum. Core specimens (diameter $110 \mathrm{~mm}$ ) were obtained from vertical boreholes drilled from Lilla tunnel floor in a zone of small anhydrite and gypsum content. Dry-coring and a single tube barrelling were used to avoid alteration induced by liquid water. Specimens for laboratory testing were obtained from the same borehole at depths varying between $5.7 \mathrm{~m}$ and $6.2 \mathrm{~m}$. Two sets of samples (Sets 1 and 2), which refer to specimens prepared and tested at two different stages, were tested in this research. X-ray analysis on oriented aggregates showed an average clayey fraction around $52.4 \%$ (composed of illite - the main component - paligorskyte and kaolinite); the dolomite, calcite and quartz contents were $19 \cdot 6 \%, 13.3 \%$ and $10 \cdot 1 \%$ respectively. The anhydrite and gypsum contents were rather low $(0.7 \%$ and $3.9 \%$ respectively) in the specimens tested. In terms of weathering behaviour, Lilla claystone is thought to be representative of the Iberian formations listed in Table 1. Lilla claystone is the name given in this paper to Tertiary sediments covering an extensive area occupying the south-east corner of the Ebro basin. Alonso et al. (2007) describe these Tertiary soft rocks in more detail.

Figure 1(a) shows the tight arrangement of minerals of an undisturbed specimen observed in a scanning electron microscope (SEM) equipped with electron dispersive spectrometer

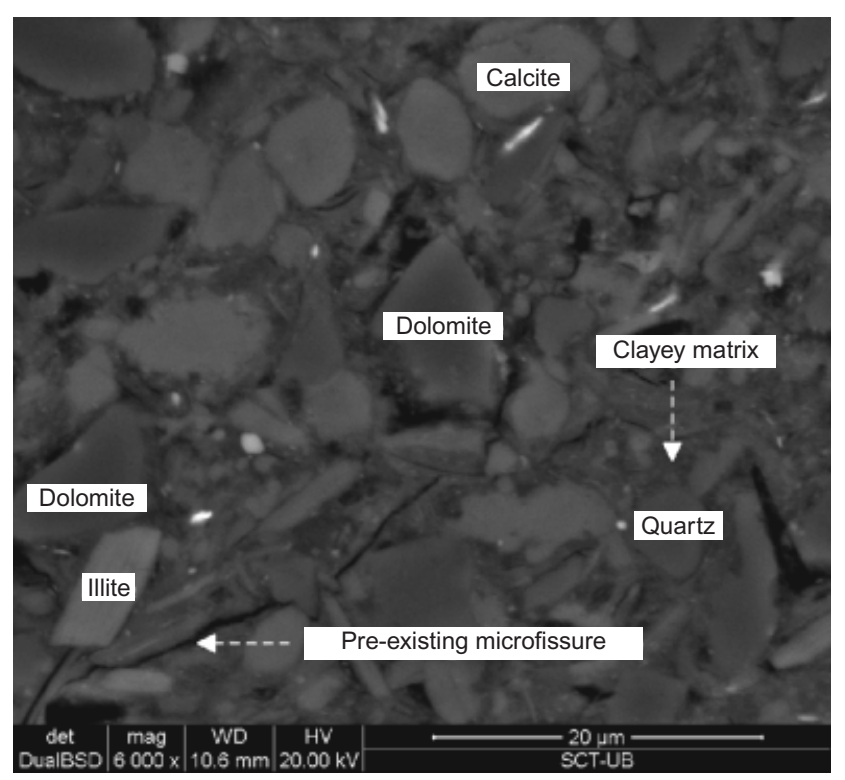

Fig. 1. Structural arrangement of undisturbed Lilla claystone
(EDS) analysis. The rock matrix may be described as a very dense clayey paste that hosts large-size minerals such as illite, dolomite, calcite and quartz. Calcite minerals do not seem to play a bonding role, because of their detrital and isolated nature. The mass fraction $<425 \mu \mathrm{m}$ has low plasticity $(\mathrm{LL} \approx 23 \%, \mathrm{PI} \approx 5 \%$ ), and as a result the clay activity is also low $(A \approx 0 \cdot 10$, determined on the basis of the determined clay content), which is consistent with the absence of expansive minerals. Tables 1 and 2 summarise the main geotechnical indices. The reported water content is expected to be lower than the in situ water content, because some drying during storage was unavoidable. However, it represents the initial condition for the applied stress paths.

The water sensitivity of Lilla claystone was studied from slake-durability tests (ASTM, 2008). The index determined, $I_{\mathrm{d} 2}=5 \%$, suggests a low durability. Three experimental techniques were used in this research: $(a)$ long-term relative humidity cycling tests; $(b)$ seismic wave velocity measurements; and $(c)$ tensile strength - splitting - tests. A brief description of each test is given below.

\section{Relative humidity cycling tests}

Long-term relative humidity cycles were applied via vapour transfer (Delage et al., 1998; Blatz et al., 2008). This technique is based on controlling the relative humidity applied to the sample boundaries. This is achieved by means of a closed system of constant vapour mass. When equilibrium is reached, the vapour concentration in the rock pores becomes equal to the externally imposed relative humidity. The thermodynamic relationship between relative humidity and total suction is given by Kelvin's law (Coussy, 1995; Gens, 2010)

$$
\psi=-\frac{R T \rho_{\mathrm{w}}}{M_{\mathrm{w}}} \ln \left(\frac{p_{\mathrm{v}}}{p_{\mathrm{v}}^{0}}\right)
$$

where $R$ is the gas constant $(8 \cdot 314472 \mathrm{~J} / \mathrm{mol} \mathrm{K}) ; T$ is the absolute temperature; $M_{\mathrm{W}}$ is the molecular mass of water $(18015 \mathrm{~g} / \mathrm{mol}) ; \rho_{\mathrm{w}}$ is density of pure water $\left(0.998 \mathrm{Mg} / \mathrm{m}^{3}\right.$ at $\left.T=20^{\circ} \mathrm{C}\right) ; p_{\mathrm{v}}$ is the partial pressure of water vapour in the air; $p_{\mathrm{v}}^{0}$ is the saturation vapour pressure at temperature $T$; and $\psi$ is the total suction. The relative humidity is given by $\mathrm{RH}=p_{\mathrm{v}} / p_{\mathrm{v}}^{0}$.

Two different experimental configurations were used to control relative humidity, depending on the stress level applied. In unstressed tests, samples were placed inside Pyrex desiccators on a porous disc above a solution that generates a given vapour pressure environment (see Fig. 2(a)). Vapour transfer was controlled by pure diffusion. A continuous record of relative humidity and temperature inside the desiccators was obtained using a digital hygrometer. Periodic volume and weight measurements were made. The evolution of rock stiffness was also determined, as explained below.

In confined tests, relative humidity cycling was applied inside a high-pressure triaxial apparatus developed to induce and track the hydromechanical degradation of argillaceous rocks. Axial and radial displacements were recorded locally. Relative humidity was controlled on the upper and lower platens. Fig. 2(b) shows the scheme of testing arrangements. Experimental details are described in Pineda (2012).

\section{Seismic wave velocity measurements}

Shear wave (bender elements) and longitudinal wave (ultrasonic pulses) velocity measurements were performed to evaluate the evolution of rock stiffness during relative humidity cycling. Bender elements were used to generate and 
Table 1. Mineralogy and geotechnical indices of undisturbed claystones

\begin{tabular}{|c|c|c|c|c|c|c|c|c|c|c|}
\hline Soil & Formation & Age: Ma & Mineralogy & Porosity & $\begin{array}{l}\text { Dry density: } \\
\mathrm{Mg} / \mathrm{m}^{3}\end{array}$ & $\begin{array}{l}\text { Consistency } \\
\text { limits }\end{array}$ & $\begin{array}{l}\text { Two-cycle } \\
\text { slaking } \\
\text { durability test, } \\
I_{\mathrm{d} 2}: \%\end{array}$ & $\begin{array}{l}\text { Unconfined } \\
\text { compression } \\
\text { strength: } \mathrm{MPa}\end{array}$ & $\begin{array}{l}\text { Tensile } \\
\text { strength: } \\
\text { MPa }\end{array}$ & References \\
\hline Opalinus clay & Middle Jurassic & $171-176$ & $\begin{array}{l}\text { Carbonates (calcite) } 6-22 \% \text { Quartz } \\
10-27 \% \\
\text { Clay constituents } 44-80 \%\end{array}$ & $0 \cdot 14-0 \cdot 18$ & $2 \cdot 22-2 \cdot 33$ & $\begin{array}{l}w_{\mathrm{L}}=33-43 \% \\
\mathrm{PI}=12-18 \%\end{array}$ & - & $4-22$ & $>1$ & $\begin{array}{l}\text { Gens et al. } \\
\text { (2007); Romero } \\
\text { et al. }(2012) \text {; }\end{array}$ \\
\hline $\begin{array}{l}\text { Callovo-Oxfordian } \\
\text { mudstone }\end{array}$ & $\begin{array}{l}\text { Upper/Middle } \\
\text { Jurassic }\end{array}$ & $156-164$ & $\begin{array}{l}\text { Calcite } 23-42 \% \\
\text { Clay constituents } 50-65 \%\end{array}$ & $0 \cdot 11-0 \cdot 16$ & $2 \cdot 21-2 \cdot 33$ & $\begin{array}{l}w_{\mathrm{L}}=21-25 \% \\
\mathrm{PI}=11-19 \%\end{array}$ & - & $10-30$ & & $\begin{array}{l}\text { Gens } \text { et al. } \\
(2007) ; \text { Gens } \\
\text { (2013) }\end{array}$ \\
\hline Abadia marl & Upper Jurassic & $145-160$ & $\begin{array}{l}\text { Carbonates (calcite and dolomite) } \\
16-23 \% \\
\text { Quartz 5-10\% } \\
\text { Clay constituents } 54-64 \% \\
\text { (kaolinite/illite) }\end{array}$ & $0 \cdot 18-0 \cdot 33$ & $1 \cdot 85-2 \cdot 25$ & $\begin{array}{l}w_{\mathrm{L}}=41-52 \% \\
\mathrm{PI}=20-25 \%\end{array}$ & $\begin{array}{l}\text { Weathered } \\
\text { sample } 17-29 \\
\text { Unweathered } \\
\text { sample } 43-75\end{array}$ & $6-14$ & $0 \cdot 5-2$ & $\begin{array}{l}\text { Alonso et al. } \\
\text { (2010); Cardoso } \\
\text { \& Alonso (2009) }\end{array}$ \\
\hline Weald siltstone & Lower Cretaceous & $125-130$ & $\begin{array}{l}\text { Calcite } \\
\text { Quartz } \\
\text { Muscovite } \\
\text { Kaolinite }\end{array}$ & $0 \cdot 17-0 \cdot 33$ & $1 \cdot 85-2 \cdot 30$ & $\begin{array}{l}w_{\mathrm{L}}=24-35 \% \\
\mathrm{PI}=10-15 \%\end{array}$ & $\begin{array}{l}\text { Weathered } \\
\text { sample } 15-40 \\
\text { Unweathered } \\
\text { sample } 65-90\end{array}$ & $1-20$ & & Pineda (2012) \\
\hline Lilla claystone & Eocene & $40-50 \mathrm{Ma}$ & $\begin{array}{l}\text { Dolomite } 11-13 \% \\
\text { Quartz } 2-7 \% \\
\text { Anhydrite } 13-28 \% \\
\text { Gypsum } 0-7 \% \\
\text { Clay constituents } 51-67 \% \\
\text { (illite/paligorskite) }\end{array}$ & $\sim 0 \cdot 12$ & $2 \cdot 39-2 \cdot 51$ & $\begin{array}{c}w_{\mathrm{L}}=23-25 \% \\
\mathrm{PI}=8 \%\end{array}$ & 5 & $17-170$ & $0 \cdot 3-2 \cdot 9$ & $\begin{array}{l}\text { Alonso et al. } \\
\text { (2013); Pineda } \\
\text { (2012) }\end{array}$ \\
\hline Pamplona marl & Upper Eocene & $34-37 \mathrm{Ma}$ & $\begin{array}{l}\text { Calcite } 50 \% \\
\text { Quartz } 20 \% \\
\text { Clay constituents } 30 \% \text { (illite/chlorite) }\end{array}$ & $0 \cdot 15-0 \cdot 19$ & $2 \cdot 12-2 \cdot 20$ & $\begin{array}{l}w_{\mathrm{L}}=27-50 \% \\
\mathrm{PI}=16-22 \%\end{array}$ & - & $15-20$ & & $\begin{array}{l}\text { Alonso et al. } \\
\text { (2010); Pineda } \\
\text { (2012) }\end{array}$ \\
\hline
\end{tabular}


Table 2. Index properties of clayey fraction and main characteristics of undisturbed specimens

\begin{tabular}{l|c|c|c|c|c|c|c}
\hline Depth: $\mathrm{m}$ & LL: $\%$ & PI: \% & $w: \%$ & $\rho_{\mathrm{t}}: \mathrm{Mg} / \mathrm{m}^{3}$ & $\rho_{\mathrm{d}}: \mathrm{Mg} / \mathrm{m}^{3}$ & $\rho_{\mathrm{s}}: \mathrm{Mg} / \mathrm{m}^{3}$ & $e$ \\
\hline $5 \cdot 4-6 \cdot 7$ & $23-25$ & 8 & $3 \cdot 2-4 \cdot 1$ & $2 \cdot 59 \pm 0 \cdot 01$ & $2 \cdot 50 \pm 0 \cdot 01$ & $2 \cdot 80 \pm 0 \cdot 02$ & $0 \cdot 115 \pm 0 \cdot 01$ \\
\hline
\end{tabular}

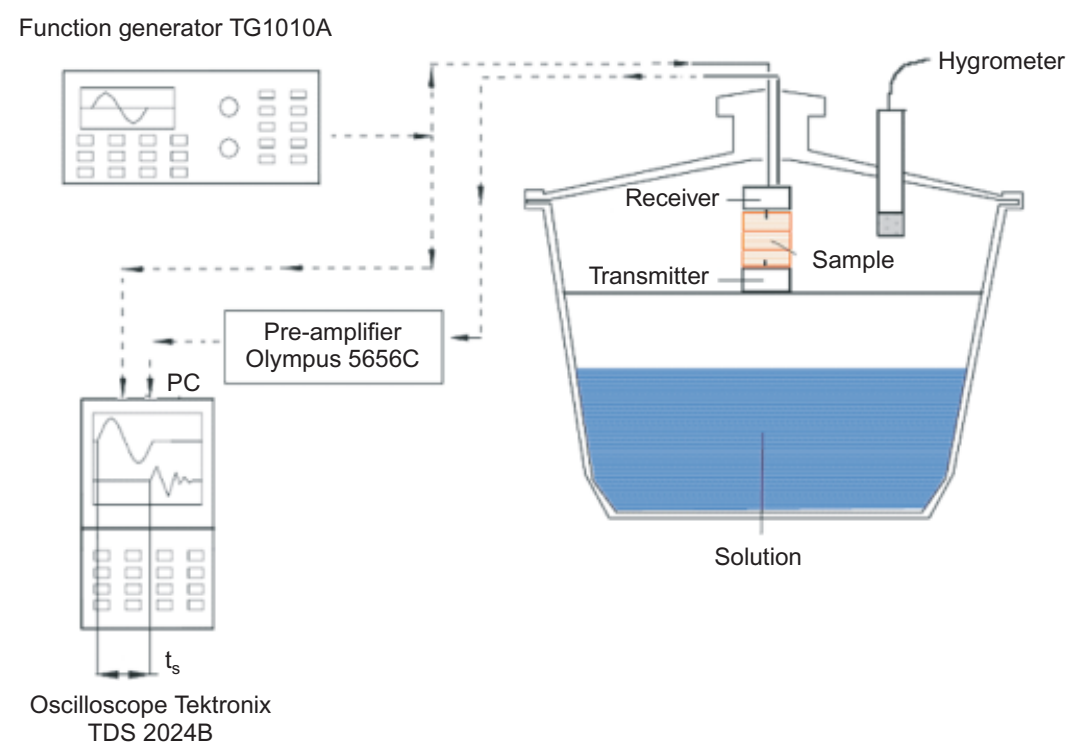

(a)

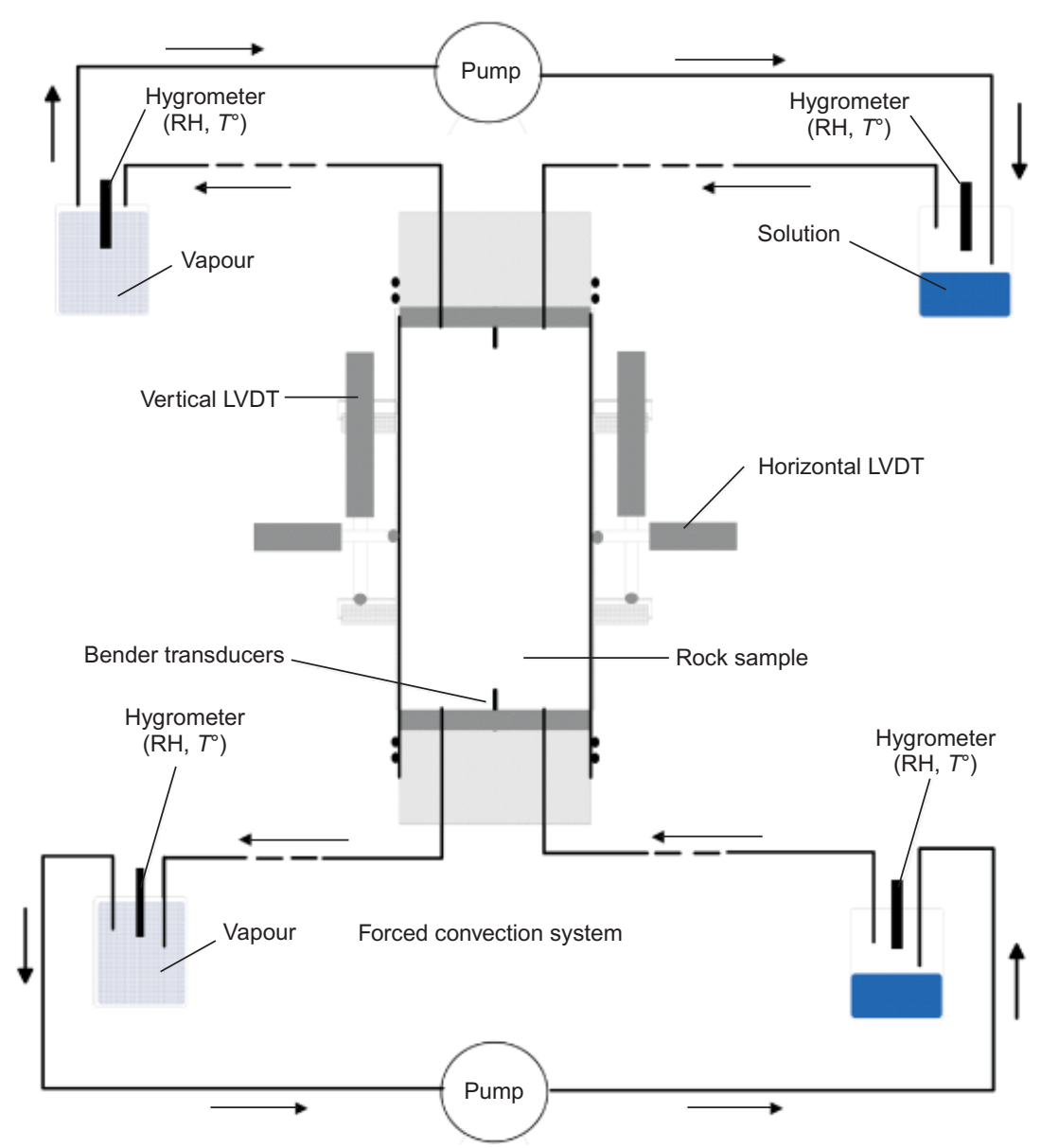

(b)

Fig. 2. Experimental set-up used to apply RH cycles: (a) vapour diffusion system; (b) forced convection system 
capture a shear disturbance travelling along the sample axis $\left(V_{\mathrm{s}(\mathrm{vh})}\right)$.

The small-strain shear stiffness was estimated as $G_{0}=\rho_{\mathrm{t}} V_{\mathrm{s}}^{2}$, where $\rho_{\mathrm{t}}$ is the total density and $V_{\mathrm{s}}=l_{\text {eff }} / t_{\mathrm{s}}$. The wave travel distance, $l_{\text {eff }}$, was taken as the distance between transducer tips (Viggiani \& Atkinson, 1995). The arrival time, $t_{\mathrm{s}}$, was determined by analysing the received trace and looking for the first significant amplitude excursion in the time domain, as described in Arroyo et al. (2010) and Pineda (2012).

Longitudinal wave velocity $\left(V_{\mathrm{L}}\right)$ measurements were periodically performed during relative humidity cycling (typically at the end of each hydraulic path), using an ultrasonic pulse device.

\section{Tensile strength tests}

The influence of relative humidity cycling on tensile strength was evaluated by means of splitting (Brazilian) tests. Tensile strength was indirectly determined on undisturbed as well as degraded samples (after relative humidity cycling) following the ISRM (1978) suggested procedure.

\section{EXPERIMENTAL PROGRAMME}

The factors controlling the degradation of argillaceous rocks induced by relative humidity cycling investigated here are

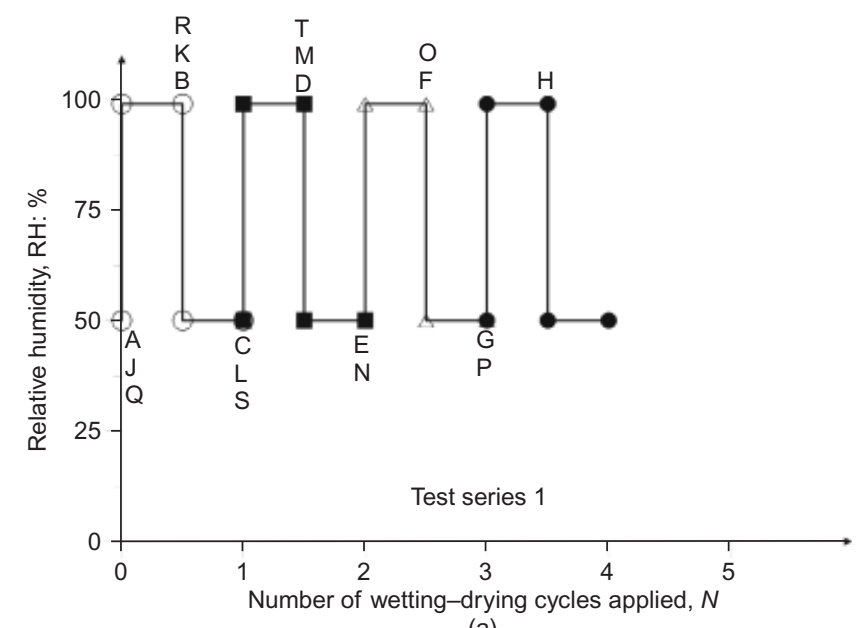

(a)

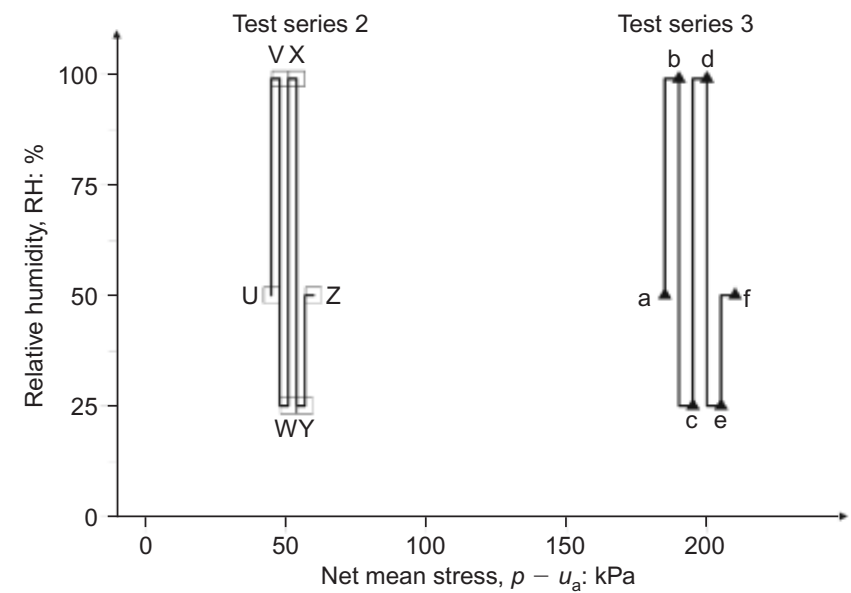

(c) (a) the number of applied cycles, $N$

(b) their amplitude, $\Delta \mathrm{RH}$

(c) the net mean stress applied to the specimens, $p-u_{\mathrm{a}}$, where $p$ is the total mean stress and $u_{\mathrm{a}}$ is the air pressure

(d) the effect of the fluid used to induce rock saturation (vapour or liquid water).

Figure 3 and Tables 3 and 4 define the tests performed.

In Test Series $1 \quad\left(p-u_{\mathrm{a}}=0 \mathrm{kPa} ; 50 \%<\mathrm{RH}<99 \%\right)$, specimens were subjected up to four long-term relative humidity cycles inside the Pyrex desiccators (see Fig. 3(a)). Table 3 provides the initial conditions and suction paths of the samples tested. Distilled water was used to induce a quasi-saturation state $(\mathrm{RH} \approx 99 \%)$, whereas drying at laboratory room conditions $\left(T=20 \pm 0 \cdot 5^{\circ} \mathrm{C}\right)$ led to $\mathrm{RH} \approx 50 \%$. Fifteen undisturbed triaxial samples $(38 \mathrm{~mm} \times 76 \mathrm{~mm}$ and $50 \mathrm{~mm} \times 100 \mathrm{~mm}$ ), divided into two sets, were subjected to Test Series 1. In addition, eight samples $(\phi=50 \mathrm{~mm}$ and $h=20 \mathrm{~mm}$ ) within Test Series 1 were also subjected to relative humidity cycling prior to determination of the tensile strength from splitting tests. Table 3 also indicates the hydraulic path applied, and the initial values of $E$ and $G$ determined by seismic wave velocity measurements. In all cases, equalisation to a given relative humidity was considered complete when no appreciable change in water content and volumetric strain was recorded after 5 days.

In Test Series $2\left(p-u_{\mathrm{a}}=50 \mathrm{kPa} ; 20 \%<\mathrm{RH}<99 \%\right)$, a $50 \mathrm{~mm} \times 100 \mathrm{~mm}$ triaxial sample was subjected to two longterm relative humidity cycles under a net confining stress

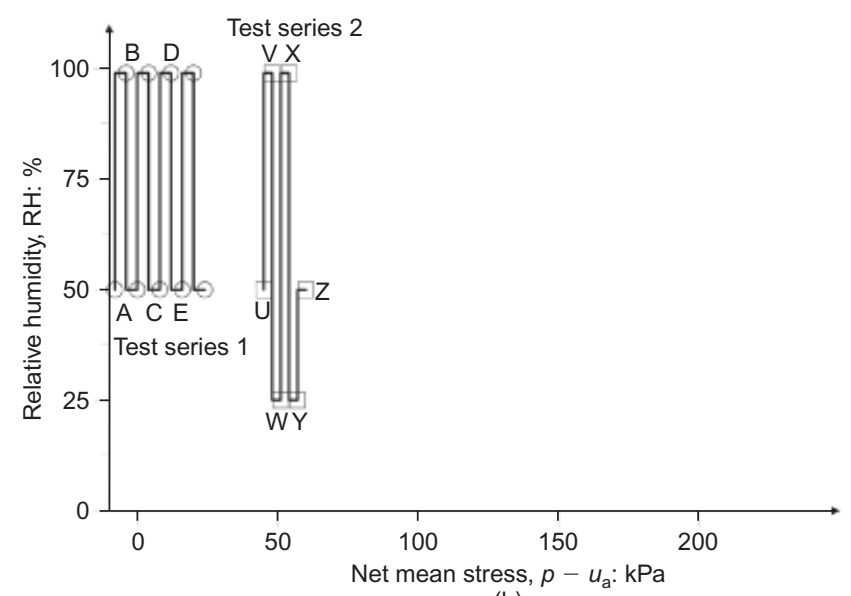

(b)

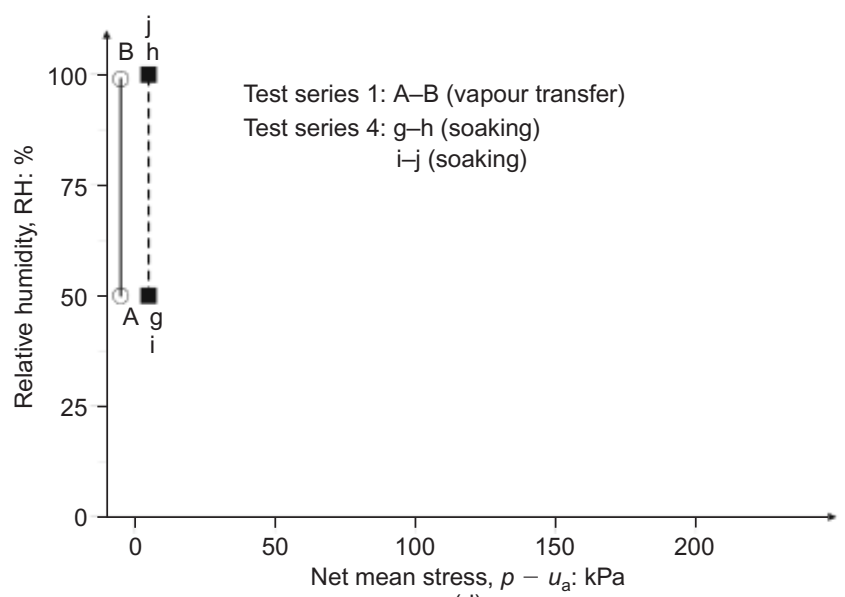

(d)

Fig. 3. (a) RH cycles for unstressed samples of Test Series 1; (b) RH-net mean stress paths for Test Series 1 and 2; (c) RH-net mean stress paths for Test Series 2 and 3; (d) RH cycles for Test Series 1 and 4 
Table 3. Stress paths applied in tests

\begin{tabular}{l|c|c|c|l|c}
\hline Test series & $p-u_{\mathrm{a}}: \mathrm{kPa}$ & $N_{\max }$ & $\mathrm{RH}_{\min }-\mathrm{RH}_{\max }: \%$ & Fluid & Time: days \\
\hline 1 & 0 & 4 & $50-99$ & Vapour & 390 \\
2 & 50 & 2 & $20-99$ & Vapour & 300 \\
3 & 200 & 2 & $20-99$ & Vapour & 300 \\
4 & 0 & Soaking & $50-100$ & Liquid water & 2 \\
\hline
\end{tabular}

Table 4. Geometry, moduli and stress suction paths imposed to samples tested

\begin{tabular}{|c|c|c|c|c|c|c|}
\hline Set & Specimen & $\phi \times h: \mathrm{mm}^{2}$ & $E_{0}: \mathrm{GPa}$ & $G_{0}: \mathrm{GPa}$ & Test series & Path \\
\hline \multirow[t]{8}{*}{1} & 38 mm_S2 & \multirow[t]{12}{*}{$38 \times 76$} & $27 \cdot 60$ & - & \multirow[t]{15}{*}{1} & A-I \\
\hline & $38 \mathrm{~mm} \_\mathrm{S} 3$ & & $28 \cdot 38$ & - & & $\mathrm{A}-\mathrm{B}$ \\
\hline & 38 mm_S4 & & $29 \cdot 20$ & - & & $\mathrm{A}-\mathrm{C}$ \\
\hline & 38 mm_S5 & & $28 \cdot 17$ & - & & A-I \\
\hline & 38 mm_S6 & & $28 \cdot 00$ & - & & A-D \\
\hline & 38 mm_S7 & & $27 \cdot 38$ & - & & A-E \\
\hline & 38 mm_S8 & & $29 \cdot 52$ & - & & A-I \\
\hline & 38 mm_S11 & & $27 \cdot 65$ & - & & $\mathrm{A}-\mathrm{B}$ \\
\hline \multirow[t]{19}{*}{2} & 38 mm_S3N & & $30 \cdot 42$ & $12 \cdot 28$ & & $\mathrm{~J}-\mathrm{N}$ \\
\hline & 38 mm_S4N & & $30 \cdot 55$ & $8 \cdot 30$ & & $\mathrm{~J}-\mathrm{P}$ \\
\hline & 38 mm_S5N & & 31.91 & $10 \cdot 81$ & & $\mathrm{~J}-\mathrm{P}$ \\
\hline & 38 mm_S4_1 & & $31 \cdot 36$ & $12 \cdot 87$ & & $\mathrm{~J}-\mathrm{K}$ \\
\hline & $50 \mathrm{~mm} \_\mathrm{S} 1^{-}$ & \multirow[t]{3}{*}{$50 \times 100$} & $34 \cdot 80$ & $14 \cdot 70$ & & $\mathrm{Q}-\mathrm{T}$ \\
\hline & 50 mm_S2 & & $34 \cdot 60$ & $15 \cdot 11$ & & $\mathrm{Q}-\mathrm{S}$ \\
\hline & 50 mm_S4 & & $34 \cdot 60$ & $15 \cdot 90$ & & $\mathrm{Q}-\mathrm{R}$ \\
\hline & SBT_1N & \multirow[t]{8}{*}{$50 \times 20$} & $28 \cdot 1$ & NA & \multirow[t]{8}{*}{$1^{*}$} & Unalt. \\
\hline & SBT_2N & & $28 \cdot 27$ & & & A-E \\
\hline & $\mathrm{SBT}_{2} 3 \mathrm{~N}$ & & 28.93 & & & A-B \\
\hline & SBT_4N & & $30 \cdot 68$ & & & A-I \\
\hline & SBT_1 & & $31 \cdot 59$ & & & Unalt. \\
\hline & SBT_2 & & $32 \cdot 76$ & & & A-D \\
\hline & SBT_3 & & $31 \cdot 63$ & & & A-I \\
\hline & SBT_4 & & $30 \cdot 14$ & & & $\mathrm{~A}-\mathrm{C}$ \\
\hline & 50 mm_SN1 & $50 \times 100$ & $30 \cdot 8$ & $12 \cdot 7$ & 2 & $\mathrm{U}-\mathrm{Z}$ \\
\hline & 50 mm_S3 & $50 \times 100$ & $35 \cdot 8$ & $16 \cdot 57$ & 3 & $a-f$ \\
\hline & 50 mm_S3N & $50 \times 100$ & $30 \cdot 4$ & $12 \cdot 44$ & $4^{* *}$ & $\mathrm{~g}-\mathrm{h}$ \\
\hline & 38 mm_ST1 & $38 \times 76$ & $29 \cdot 82$ & $12 \cdot 31$ & & $i-j$ \\
\hline
\end{tabular}

\footnotetext{
* Splitting tests

** Soaking tests.

NA: Not applicable
}

$p-u_{\mathrm{a}}=50 \mathrm{kPa} \quad$ (path U-Z, Fig. 3(b)). Distilled water $(\mathrm{RH} \approx 99 \%)$ was employed for wetting, whereas a lithium chloride solution was used to apply $\mathrm{RH}=20 \%$. Therefore the sample was subjected to a change in relative humidity, $\Delta \mathrm{RH}=80 \%$. Equilibrium at a given $\mathrm{RH}$ was assumed complete when no appreciable change in volumetric strain was observed after 7 days. Changes in rock stiffness were continuously monitored by means of bender elements tests.

Test Series $3\left(p-u_{\mathrm{a}}=200 \mathrm{kPa} ; 20 \%<\mathrm{RH}<99 \%\right)$ involved the application of two long-term relative humidity cycles on a undisturbed $50 \mathrm{~mm} \times 100 \mathrm{~mm}$ sample under a confining stress $p-u_{\mathrm{a}}=200 \mathrm{kPa}$. RH cycling and the equilibrium criterion were similar to Test 2 (path $\mathrm{a}-\mathrm{f}$ in Fig. 3(c)). Bender elements measurements were used to track the evolution of rock stiffness.

In Test Series $4\left(p-u_{\mathrm{a}}=0 \mathrm{kPa}\right.$; RH: $\left.50 \% \rightarrow 100 \%\right)$, two undisturbed samples were subjected to soaking under unstressed conditions. Samples were covered with latex membranes to avoid sample disintegration, and then were placed in contact with distilled water through their bottom (sample Set 2_50 mm) or their peripheral contour using a syringe (sample Set 2_38 mm). Shear wave velocity was periodically measured during the first $48 \mathrm{~h}$ of soaking. Volume changes were not determined because of measuring difficulties.

The influence of the number of RH cycles $(N)$ was evaluated in Test Series 1. The influence of the amplitude of the relative humidity change $(\Delta \mathrm{RH})$ was studied by comparing the results obtained from Test Series 2 with those obtained during the first two cycles in Test Series 1. The effects of the stress level $\left(p-u_{\mathrm{a}}\right)$ were evaluated by comparing results from Test Series 3 and Test Series 2. Finally, the influence of the fluid used during wetting was analysed by comparing results from Test Series 4 and Test Series 1 (only for the first wetting path).

\section{RELATIVE HUMIDITY CYCLES $(N)$}

Figure 4 shows the water retention curve (WRC) obtained from six undisturbed specimens using a dew-point chilled mirror psychrometer (WP4). The test followed the procedure suggested by Cardoso et al. (2007). Up to three RH cycles were applied in this case using vapour during wetting paths. It can be seen that the hydraulic behaviour of the undisturbed rock remained inside the main wetting and drying branches obtained during the first $\mathrm{RH}$ cycle. This result suggests that the water retention properties were not affected by the RH cycling using vapour. However, a different behaviour was observed when specimens were previously exposed to liquid water. Fig. 4 also includes the WRC for specimens previously subjected to the slaking test (three cycles: liquid 


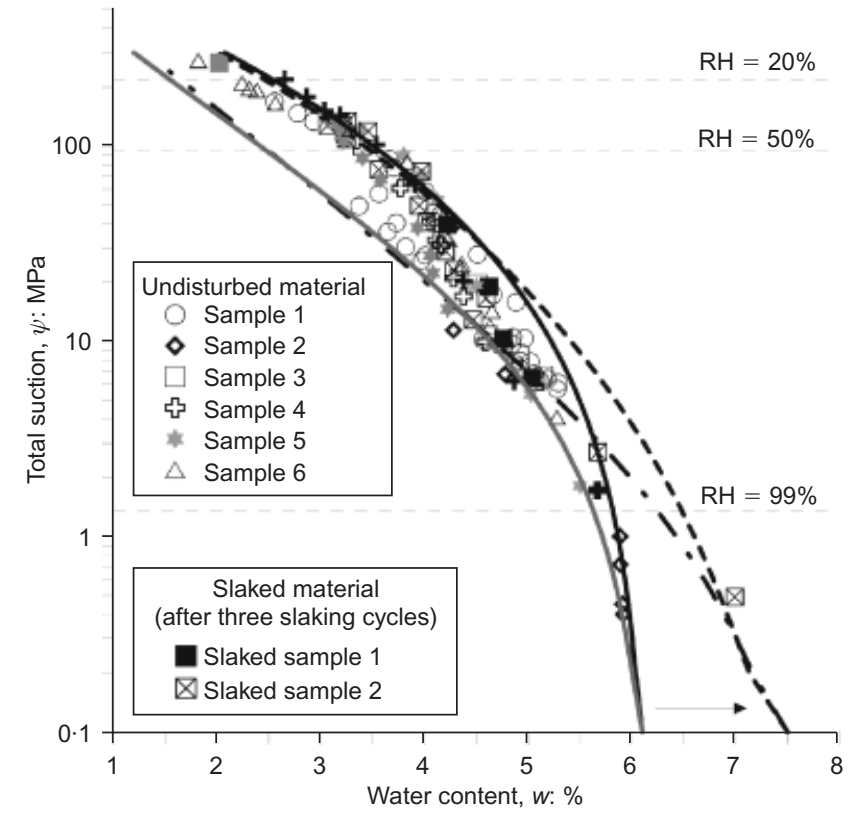

Fig. 4. Water retention curves for undisturbed and degraded materials water + oven-drying at $105^{\circ} \mathrm{C}$ ). In this case, a higher water retention capacity was displayed by the slaked material in the low suction range $(\psi<8 \mathrm{MPa})$. At high suctions, where the water retention capacity is controlled mainly by the specific surface of the clayey fraction, undisturbed and slaked materials showed a similar response. This behaviour underlines the importance of liquid water in the degradation process. Similar results have recently been reported by Cardoso et al. (2010) for Abadia marls (Portugal).

Figure 5 shows the temporal evolution of water content and volumetric strain for specimens subjected to Test Series 1. RH and temperature measurements inside the Pyrex desiccators are also included. It took 390 days to apply four cycles. RH cycling induced a progressive volumetric expansion of the rock with negligible variations in the maximum water retention capacity of the rock. The amplitude of relative humidity cycles applied in Test Series 1 $(\Delta \mathrm{RH} \approx 50 \%)$ induced a suction change of around $94 \mathrm{MPa}$, but a relatively small variation of water content $(3 \cdot 15 \%<w<5 \cdot 5 \%)$. Samples from Set 2_50 mm showed lower values of water content at the end of wetting, which was in agreement with its slightly higher initial dry density. Longer equalisation times were required in this case, owing to the larger sample size (see Fig. 5(c)). In all cases, drying was more efficient (in time) than wetting to reach the

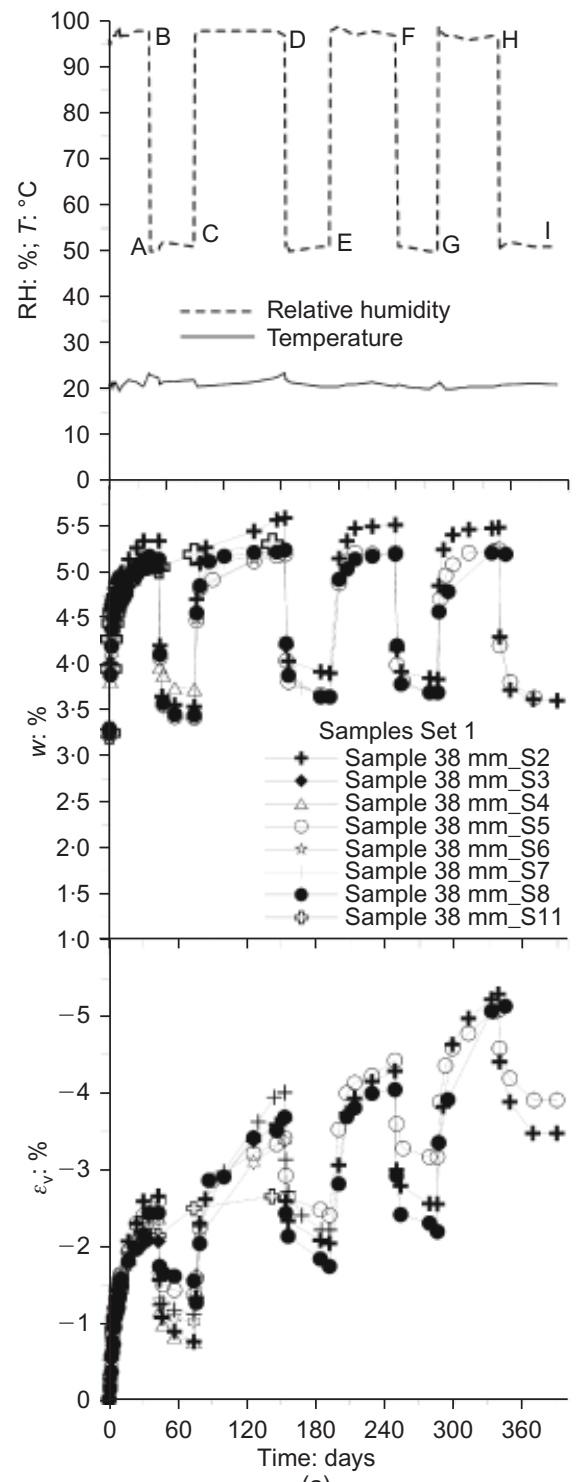

(a)

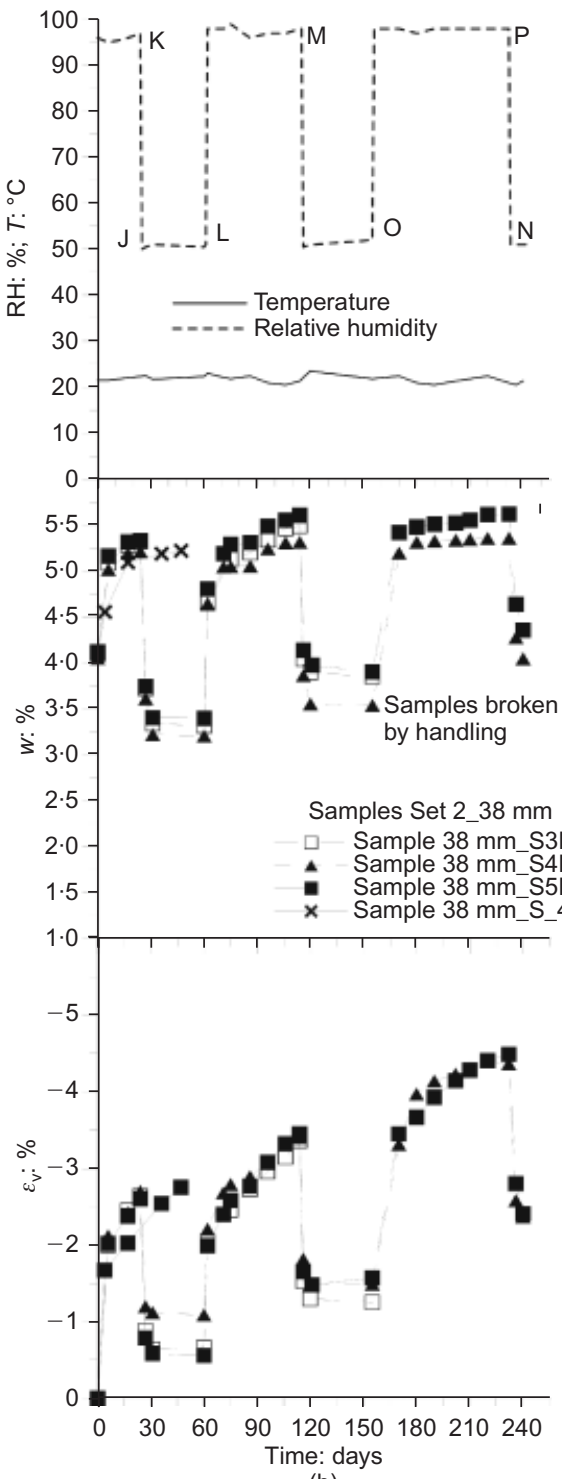

(b)

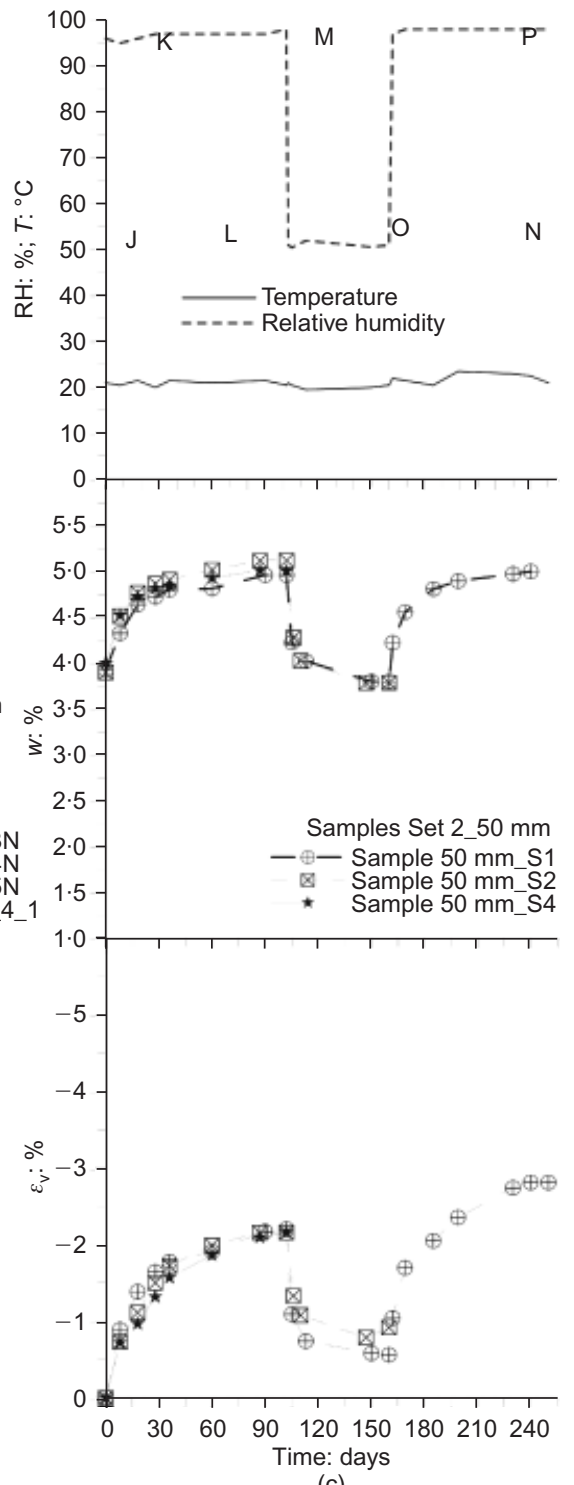

(c)

Fig. 5. Evolution of water content and volumetric strain during Test Series $1\left(\Delta \mathrm{RH} \approx 50 \%, p-u_{\mathrm{a}}=0 \mathrm{kPa}, N=\mathrm{up}\right.$ to 4$)$ 
equilibrium. This means that the rate of water absorption was always lower than water desorption.

The kinetics of water transfer during Test Series 1 was analysed through the concept of the moisture diffusivity coefficient $\left(D_{\mathrm{w}}\right)$, which accounts for vapour and liquid transfer. Values of $D_{\mathrm{w}}$ were obtained from experimental data by using the linearised diffusion equation derived by Gardner (1956), who assumed a constant unsaturated permeability during the suction step change. The amount, $M_{\mathrm{w}}(t)$, of intruded/extracted water at time $t$ is given by (see Gardner, 1956; Vicol, 1990, for additional details)

$$
M_{\mathrm{w}}(t) \cong M_{\mathrm{w} 0}\left[1-\frac{8}{\pi^{2}} \exp \left(-\frac{\pi^{2} D_{\mathrm{w}}}{4 L^{2}}\right) t\right]
$$

where $M_{\mathrm{w} 0}$ is the total amount of intruded/extracted water in a suction step, and $L$ is the drainage length. Fig. 6(a) shows the variation of the diffusivity coefficient with total suction at the end of each hydraulic stage. The drainage length was assumed equal to $L=h_{0} / 2$, where $h_{0}$ is the sample height. $D_{\mathrm{w}}$ varied between $2.2 \times 10^{-10} \mathrm{~m}^{2} / \mathrm{s}$ and $1.5 \times 10^{-9} \mathrm{~m}^{2} / \mathrm{s}$, with higher values obtained for drying. Fig. 6(b) shows the variation of $D_{\mathrm{w}}$ with the number of RH cycles applied $(N)$. As observed, no important changes in $D_{\mathrm{w}}$ were obtained with the application of the $\mathrm{RH}$ cycles, a result which is consistent with the response of the WRC described above. Values of $D_{\mathrm{w}}$ were used to determine rough values of the theoretical time $\left(t_{95}\right)$ required to reach the $95 \%$ of water inflow/outflow, as proposed by Delage et al. (2008)

$$
t_{95}=T_{\mathrm{V}} \frac{L^{2}}{D_{\mathrm{w}}}=1.129 \frac{L^{2}}{D_{\mathrm{w}}}
$$

where $T_{\mathrm{V}}$ is the time factor. $t_{95}$ varied between 18 days $(38 \mathrm{~mm} \times 76 \mathrm{~mm}$ specimens $)$ and 38 days $(50 \mathrm{~mm} \times$ $100 \mathrm{~mm}$ specimens) for wetting paths. It varied from 6 to 11 days for drying paths. The time applied during each hydraulic path was always at least 1.5 times the theoretical value of $t_{95}$ given by equation (3) (see Fig. 5).

A similar volumetric response was observed in all specimens. The equilibrium time of volumetric deformation, $\varepsilon_{\mathrm{v}}$, was always shorter under drying, in agreement with the highest diffusivity coefficient. Swelling took place on wetting, whereas some volume reduction (shrinkage) was observed during drying. Shrinkage was always lower than the previous swelling, leading to a progressive and cumulative swelling (see Fig. 7). The maximum volumetric swelling $(-5 \cdot 30 \%$ at point $\mathrm{H})$ occurred in samples subjected to four $\mathrm{RH}$ cycles. At the end of the fourth drying, $\varepsilon_{\mathrm{V}}$ was around $-3.75 \%$ (point I).

Owing to the sedimentary nature of Lilla claystone, strain anisotropy was observed during Test Series 1, as shown in Fig. $8(\mathrm{a})$ in terms of the axial to radial strain ratio $\left(\varepsilon_{\mathrm{a}} / \varepsilon_{\mathrm{r}}\right)$. In general, $\varepsilon_{\mathrm{a}}$ was higher than $\varepsilon_{\mathrm{r}}$. Strain ratio varied from $0 \cdot 90-1 \cdot 4$ (wetting stages) to $1 \cdot 0-2 \cdot 2$ (drying). The increase

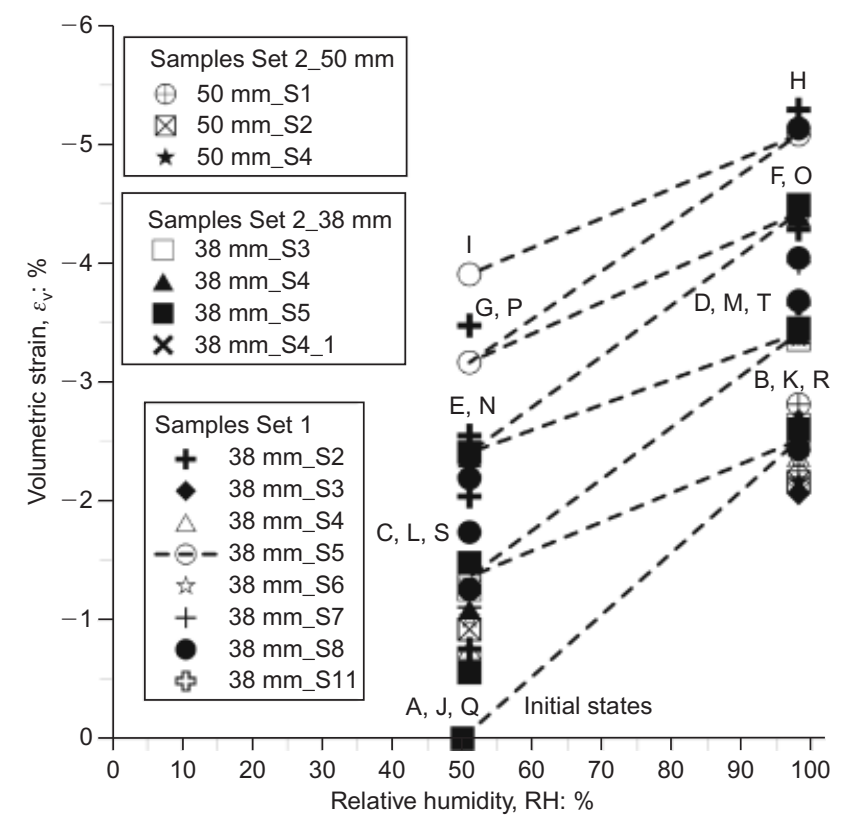

Fig. 7. Variation of volumetric deformation with RH for specimens of Test Series 1

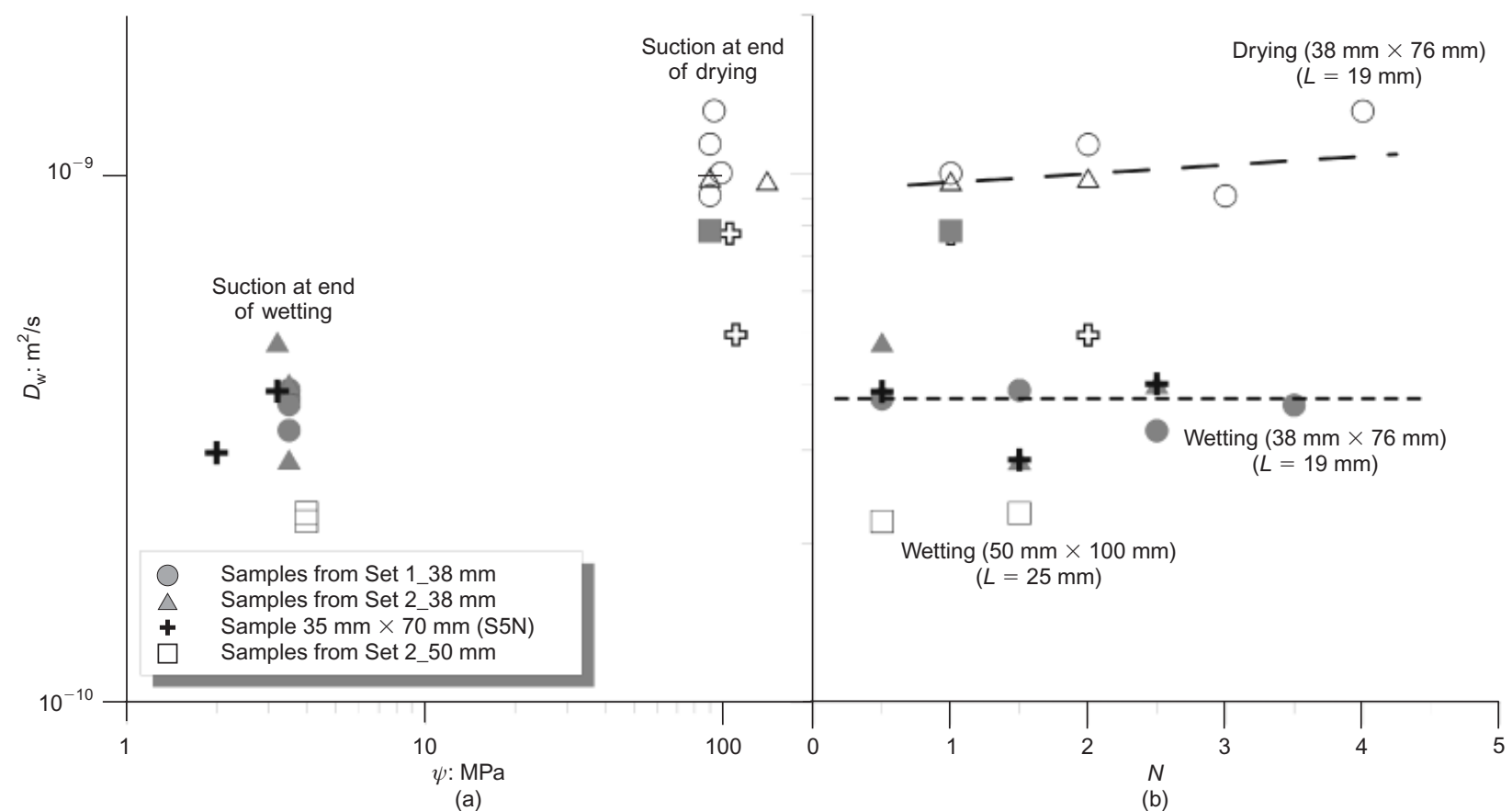

Fig. 6. Variation of diffusivity coefficient, $D_{\mathrm{w}}$ : Test Series 1 


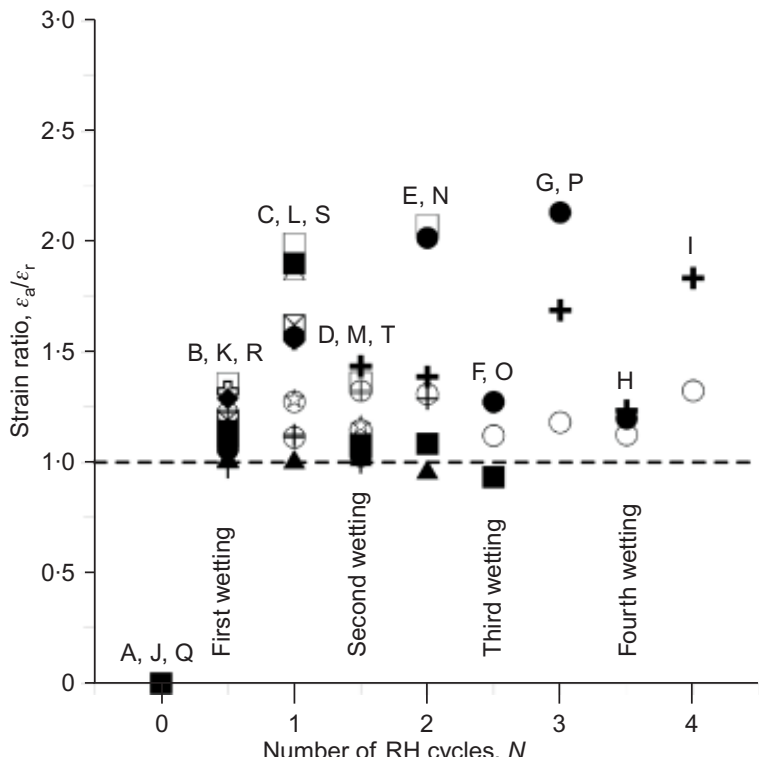

(a)

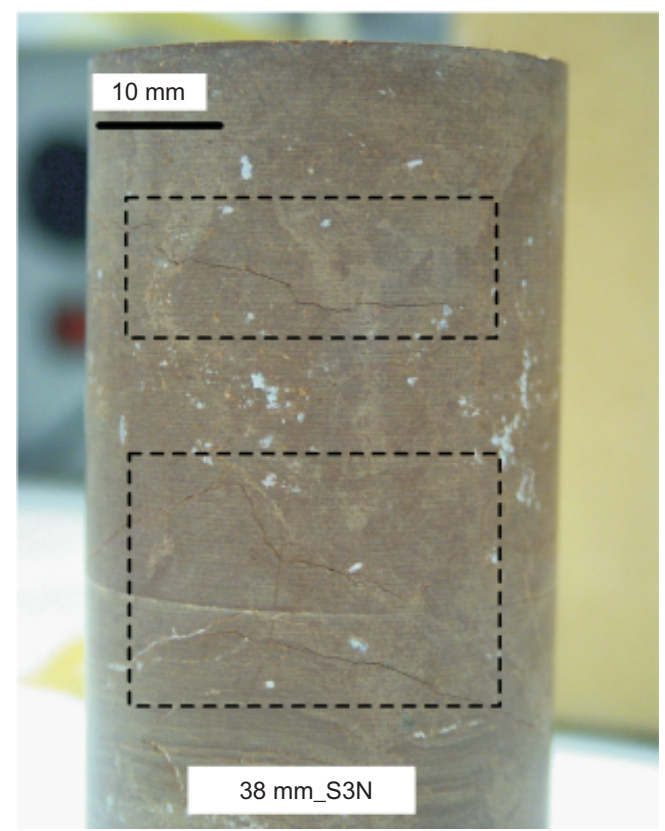

(b)

Fig. 8. (a) Evolution of strain ratio with applied suction cycles in Test Series 1; (b) development of sub-horizontal fissures in sample 38 mm_S3N

of strain ratio during drying was due to the small amount of axial shrinkage compared with radial deformation that leads in some cases to fissuring of sub-horizontal orientation which progressively came into view as observed in Fig. 8(b) for specimen $38 \mathrm{~mm} \_\mathrm{S} 3 \mathrm{~N}$. This is consistent with the orientation of samples which had the vertical axis perpendicular to bedding.

Analysis of the evolution of void ratio with water ratio $\left(e_{\mathrm{w}}=w G_{\mathrm{s}}\right)$ for sample $38 \mathrm{~mm} \_\mathrm{S} 5$ (see Fig. 9) reveals that the main consequence of the $\mathrm{RH}$ cycling was a progressive decrease of the global degree of saturation $\left(S_{\mathrm{r}}=e / e_{\mathrm{w}}\right)$ at the end of each wetting path. The explanation is that new pore volumes (expressed by $\Delta e_{1}, \Delta e_{2}, \Delta e_{3}$ and $\Delta e_{4}$ ) were not filled with water when vapour was used during wetting paths. However, in cases where liquid water is used (Test Series 4; Fig. 3(d)), it is expected that the degradation path will follow the saturation line $\left(e / e_{\mathrm{w}}=1\right)$ (e.g. Pineda \&

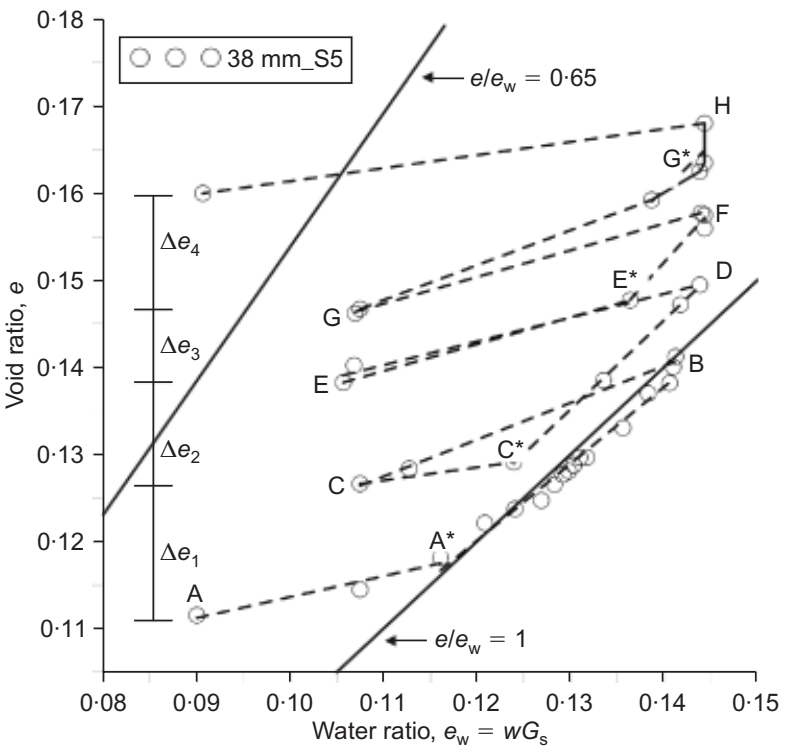

Fig. 9. Evolution of void ratio with water ratio for specimen 38 mm_S5 (Test Series 1)

Romero, 2013). The implications of this irreversible response will be analysed in the following sections.

Figure 10 shows the variation of Young's modulus $\left(E_{0}\right)$ and shear modulus $\left(G_{0}\right)$ with water ratio during Test Series 1. $E_{0}$, obtained from longitudinal wave measurements, was determined at the end of each hydraulic path. $G_{0}$, measured using bender elements, was periodically determined, but only in samples from Set 2. Initial values for $E_{0}$ ranged between $30 \mathrm{GPa}$ and $35 \mathrm{GPa}$, whereas $G_{0}$ varied from $11 \mathrm{GPa}$ to $15 \mathrm{GPa}$, with a peak value obtained for sample $50 \mathrm{~mm} \_\mathrm{S} 1$ (attributed to its high initial dry density). Dotted lines in Fig. 10 define the non-linear variation of $E_{0}$ and $G_{0}$ with water ratio at $\mathrm{RH}=99 \%$. The evolution of the rock stiffness is shown in Fig. 11 in terms of the number of RH cycles, $N$ $(0.5,1.5,2.5$ and 3.5 indicate the ends of wetting paths). Both Young's and shear moduli have been normalised against the stiffness in the initial state. Young's modulus (Fig. 11(a)) decreased during wetting phases but also along drying paths. The larger reduction in Young's modulus took place during the first cycle, where it decreased to around $0 \cdot 4 E_{0}$. Then the degradation of Young's modulus exhibited a smaller rate. A similar response was observed in terms of shear modulus (Fig. 11(b)). Previous results suggest a relationship between the degradation of the rock stiffness and the progressive volumetric expansion of the rock. This aspect will be discussed below.

The effect of RH cycling on the tensile strength of Lilla claystone was determined by means of splitting (Brazilian) tests (Test Series $1^{*}$; Table 4). Again, up to four cycles were applied via vapour transfer (path A-I). Fig. 12 shows the temporal evolution of $w$ and $\varepsilon_{\mathrm{v}}$ during $\mathrm{RH}$ cycling, which is similar to previously reported results (Fig. 5) for Test Series 1. The stress-displacement curves obtained during splitting tests showed a strong dependence on the previous $\mathrm{RH}$ cycling, as shown in Fig. 13(a). A constant displacement rate $(0.045 \mathrm{~mm} / \mathrm{min})$ was used in all tests. The steps observed in the stress-displacement curve for undisturbed Sample_B were a consequence of vertical displacement stops, of around $30 \mathrm{~s}$, during which the shear wave velocity, orthogonal to the loading axis, was determined. Peak tensile strength decreased with the application of $\mathrm{RH}$ cycles from around $2900 \mathrm{kPa}$ (undisturbed) to $200 \mathrm{kPa}$ (after four cycles).

Figure 13(b) shows the final states after the splitting tests. It was observed that microfissuring induced during the 


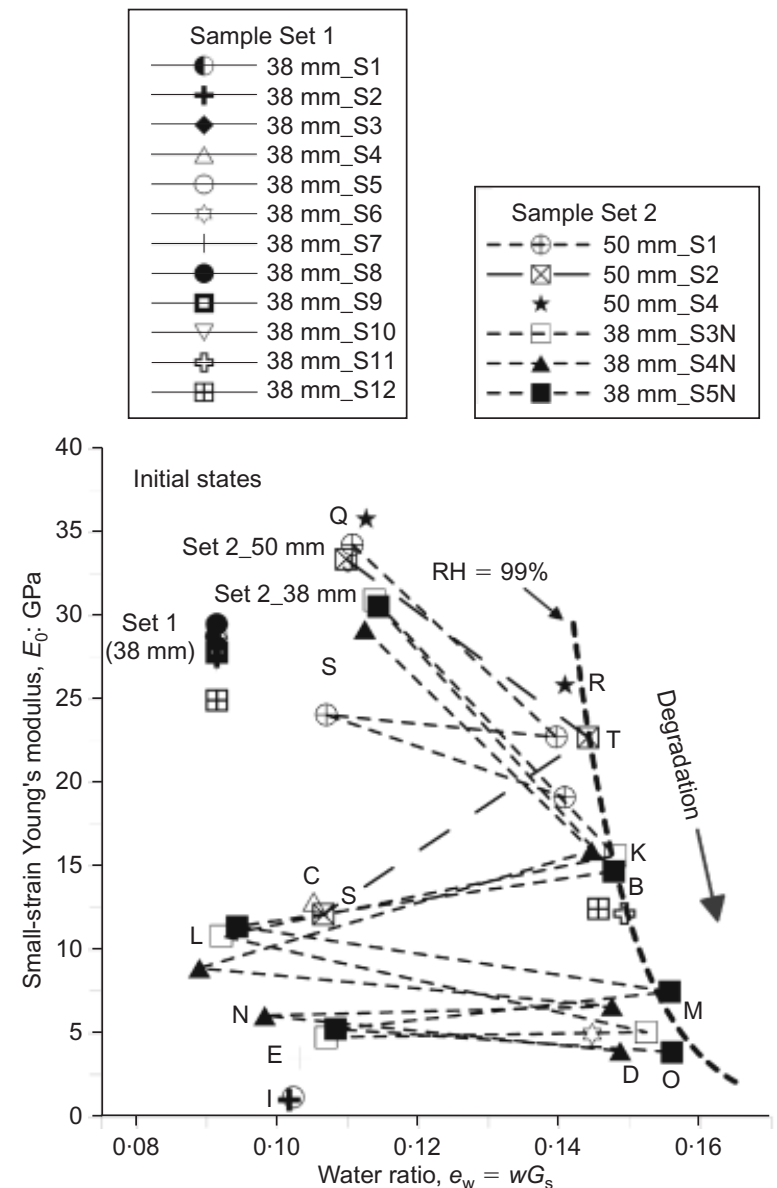

(a)

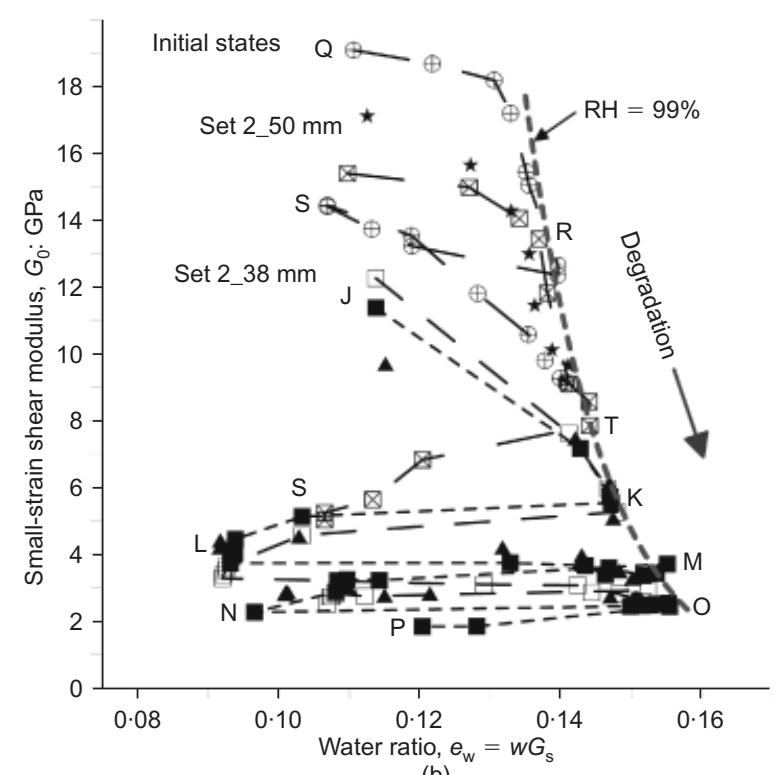

(b)

Fig. 10. Variation of (a) Young's and (b) shear modulus in Test Series $1\left(\Delta \mathrm{RH} \approx 50 \%, p-u_{\mathrm{a}}=0 \mathrm{kPa}, N=\right.$ up to 4$)$

hydraulic paths contributed to the degradation of tensile strength shown in Fig. 13(c). Tensile strength has been normalised by the averaged tensile strength obtained in undisturbed samples $\mathrm{A}$ and $\mathrm{B}\left(\sigma_{\mathrm{t} \text {-peak }} / \sigma_{\mathrm{t} 0}\right)$. The first wetting reduced the tensile strength to around $0 \cdot 40 \sigma_{\mathrm{t} 0}$, with a subsequent smaller increase during first drying to $0.47 \sigma_{\mathrm{t} 0}$.

The experimental results presented in this section indicate that rock degradation was accompanied by a progressive volumetric swelling. The first cycle induced the most signifi-

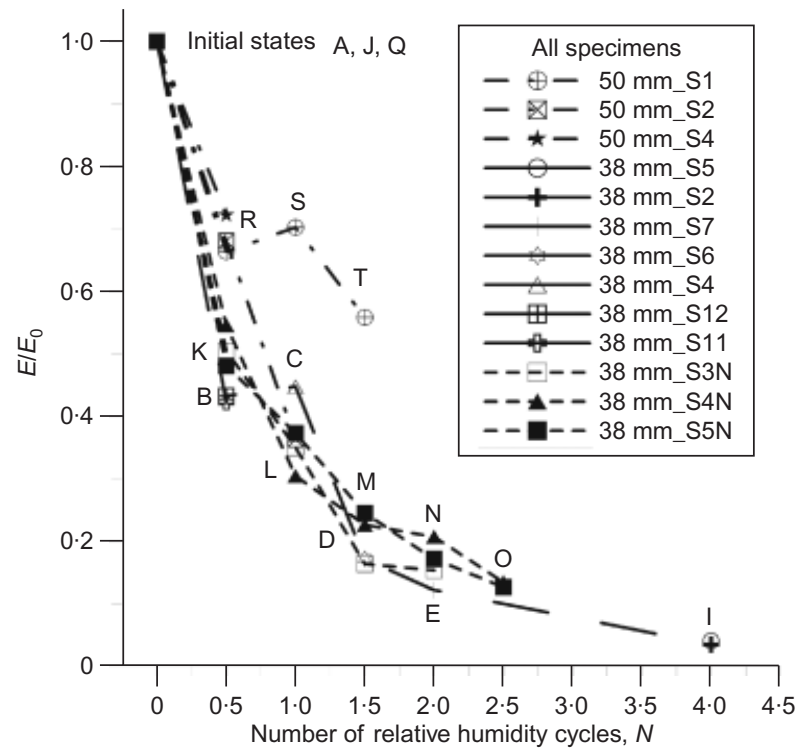

(a)

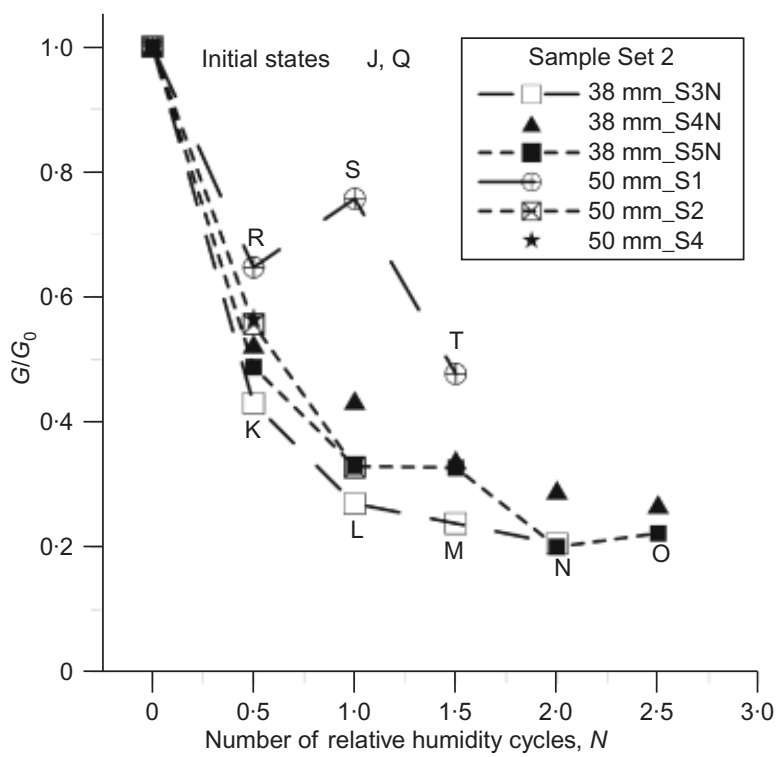

(b)

Fig. 11. Stiffness degradation with number of RH cycles in Test Series 1

cant degradation, and subsequently a decreasing degradation rate was observed. Table 5 summarises the results for all specimens subjected to Test Series 1 .

\section{AMPLITUDE OF RELATIVE HUMIDITY $(\Delta \mathrm{RH})$}

Figure 14 shows the results obtained during Test Series 2, in which the amplitude of the relative humidity increased up to $\Delta \mathrm{RH} \approx 80 \%(20 \%<\mathrm{RH}<99 \%)$. A low confining stress, $p-u_{\mathrm{a}}=50 \mathrm{kPa}$, was applied in this case. The temporal evolution of volumetric strain $\left(\varepsilon_{\mathrm{v}}\right)$ and shear wave velocity $\left(V_{\mathrm{s}}\right)$ is presented in this figure. As observed, around 300 days were required to apply two $\mathrm{RH}$ cycles. Wetting induced volumetric swelling, whereas some shrinkage was observed during drying. Drying induces sample fissuring which, in turn, enhances expansion during the wetting cycle. Table 6 provides the volumetric expansion and the shear stiffness at the end of the two RH cycles applied.

The influence of the amplitude of the relative humidity change $(\Delta \mathrm{RH})$ was examined by comparing the experimental results from Test Series 2 with those obtained during the 


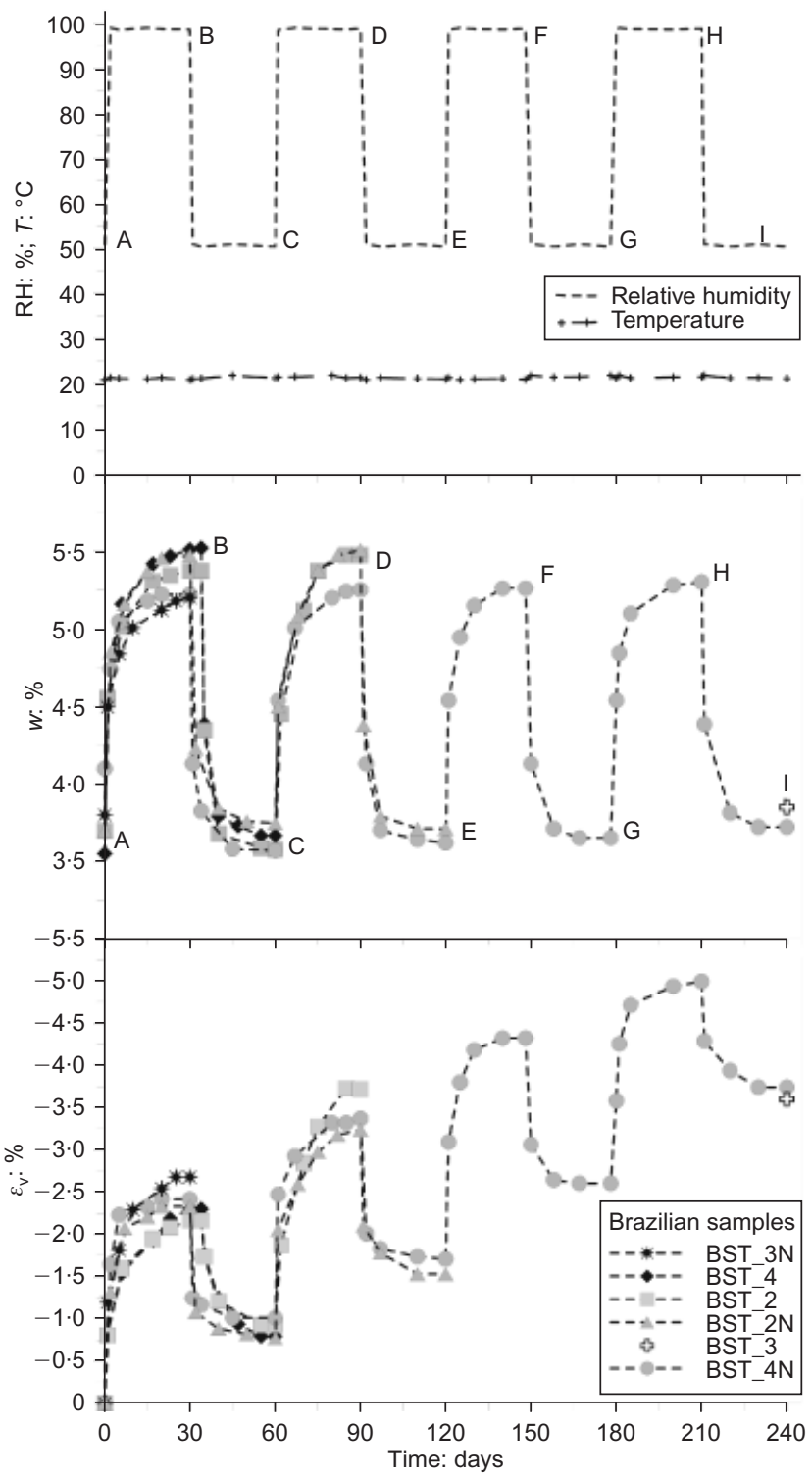

Fig. 12. Evolution of water content and volumetric strains in samples used for splitting tests (Test Series 1)

first two cycles in Test Series 1. Fig. 15(a) compares the evolution of $\varepsilon_{\mathrm{V}}$ as a function of $N$ for both tests. Higher volumetric swelling was observed in Test Series 2 as a consequence of the increase in $\Delta \mathrm{RH}$, despite the higher stress level applied in Test Series 2.

Figure 15(b) shows the evolution of the normalised shear modulus $\left(G / G_{0}\right)$ during both tests as a function of $N$. In the case of Test Series 2, the shear modulus was determined by using a constant density value during each cycle. The total density of the undisturbed specimen was used to calculate $G$ during the first cycle, whereas the final density was adopted during the second cycle. Despite a similar reduction in moduli observed at the end of the first wetting in both tests, a strong decrease in shear modulus was observed in Test Series 2 .

\section{STRESS LEVEL $\left(p-u_{\mathrm{a}}\right)$}

The evolution of $\varepsilon_{\mathrm{V}}$ and $V_{\mathrm{s}}$ in Test Series 3 is shown in Fig. 16. The net mean stress now increased to $p-u_{\mathrm{a}}=200 \mathrm{kPa}$, whereas the amplitude of the relative humidity change was maintained at $\Delta \mathrm{RH} \approx 80 \%$. Three hundred days were required to apply two RH cycles. Wetting

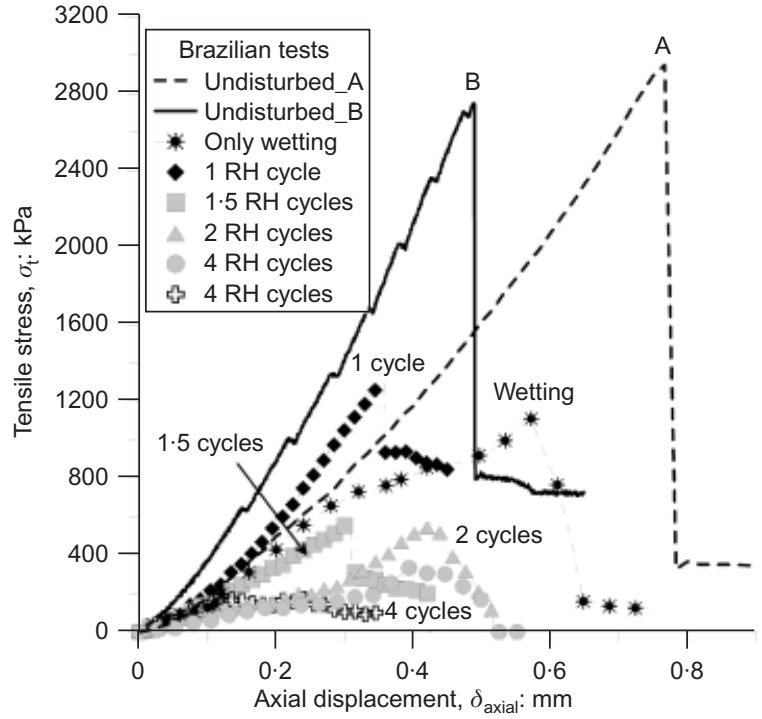

(a)
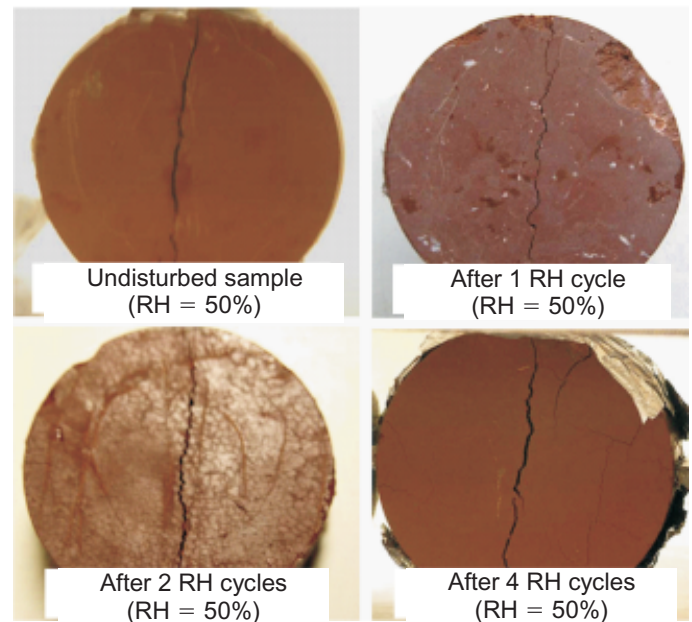

(b)

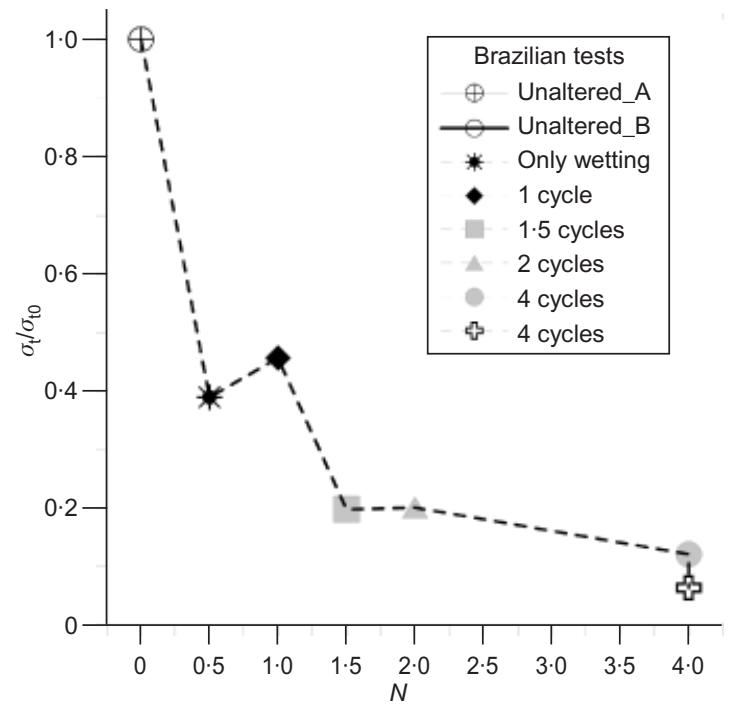

(c)

Fig. 13. Splitting tests: (a) stress-displacement curves; (b) photographs after Brazilian tests; (c) degradation of $\sigma_{\text {t-peak }}$ with $N$

induced volumetric swelling, whereas some shrinkage was observed during drying, which led to a net volumetric expansion after each cycle. Fig. 16 indicates a progressive degradation of the rock in Test 3 , expressed not only by the 


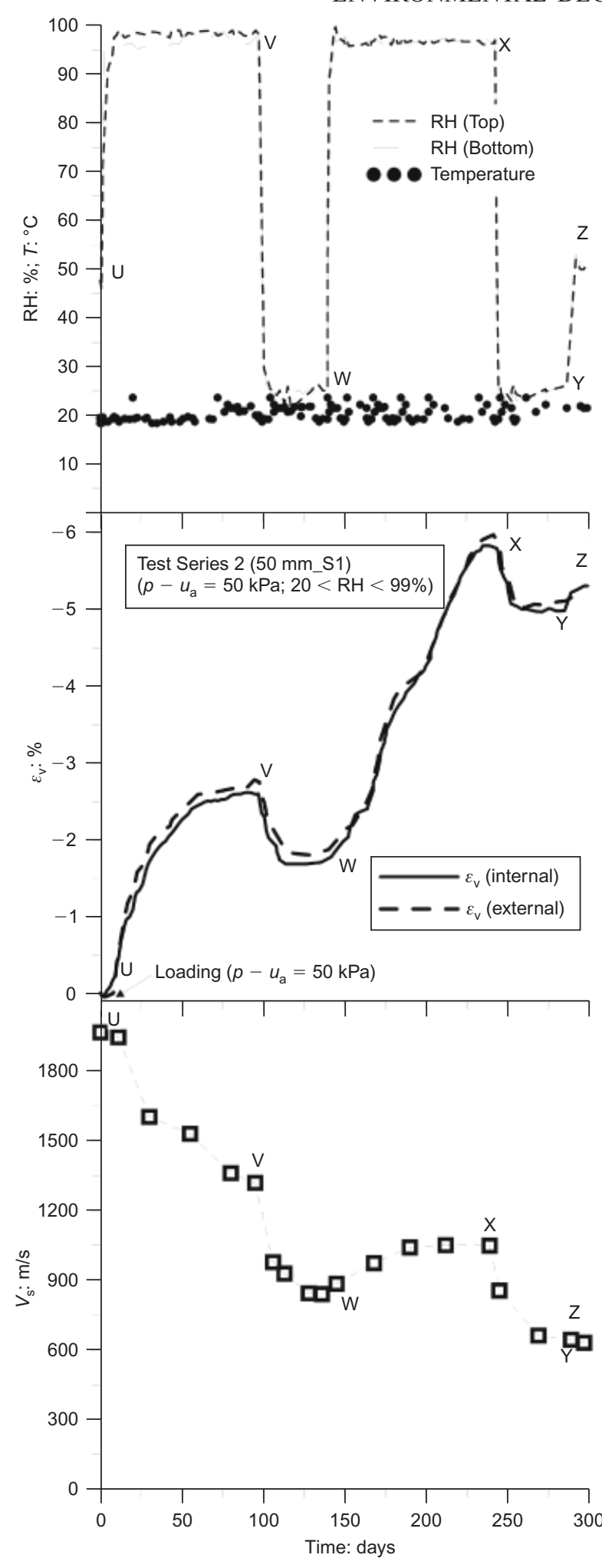

Fig. 14. Evolution of relative humidity, temperature, volumetric strain and shear wave velocity during Test Series $2(\Delta R H \approx 80 \%$, $p-u_{\mathrm{a}}=50 \mathrm{kPa}, N=2$ )

accumulated volumetric expansion, but also by the irreversible reduction in $V_{\mathrm{s}}$ after each cycle. This behaviour was qualitatively similar to the response observed in Test Series 1 and 2. Table 6 summarises the results from Test Series 3. The effect of the stress level $\left(p-u_{\mathrm{a}}\right)$ is clear when comparing the results of Test Series 3 and Test Series 2 (Fig. 17(a)). As observed, increasing confinement substantially reduces the accumulated swelling.

The effect of the stress level on the degradation of shear modulus is shown in Fig. 17(b) in terms of the evolution of $G / G_{0}$ with $N$. The shear modulus during Test Series 3 was determined by using the initial density for the first cycle and the final density for the second cycle.

Confining stress helps to reduce the degradation in Test Series 3 in terms of shear modulus. Direct observation of the sample at the end of the test also suggests that microfissuring is the main degradation mechanism. A practical upshot of the previous results shows the importance of maintaining some confinement on open faces in slopes and excavations in order to minimise the degradation of the rock.

\section{WETTING BY LIQUID WATER: EFFECT OF FULL SATURATION}

Suction control by means of vapour transfer is not a practical procedure to apply low water potentials (suctions). On the other hand, a change in suction in the vicinity of full saturation is, in general terms, a very effective procedure to induce volume changes in unsaturated soils. Therefore changing a vapour-induced procedure by a liquid water exposure of the samples was introduced to examine the effects of full saturation. Whether liquid water has an additional weathering effect beyond what is implied by a zero suction application was not further investigated in the research reported here.

Nonetheless, saturation by liquid water has a substantially increased degradation effect if compared with the vapour technique for the highest $\mathrm{RH}(\approx 99 \%)$ possible to apply in the laboratory. This is shown in Fig. 18(a) in terms of recorded expansion and in Fig. 18(b) in terms of the evolution of the shear velocities. Fig. 18(a) also shows that the sample reaction against liquid water of two undisturbed specimens, saturated by soaking at $\sigma_{\mathrm{v}}=5 \mathrm{kPa}$ under laterally confined conditions, is much faster than its response against a vapour control.

Results presented in Fig. 18(b) for the liquid water control were obtained in two undisturbed samples subjected to soaking through their bottom edge. The two unloaded cylindrical samples were covered laterally by a latex membrane. Final water contents after $V_{\mathrm{s}}$ testing were found to be $5 \cdot 35 \%$ for the vapour-controlled test and $6 \cdot 25 \%$ for the liquid-saturated specimens. This is probably an indication that the vapour-controlled samples still retained some suction at the end of the test. In fact, the WRC shown in Fig. 4 indicates that a suction in the vicinity of $2 \mathrm{MPa}$ may still exist for $w=5 \cdot 25 \%$. This suction is equivalent to $\mathrm{RH}=99 \%$ if the psychometric equation (1) is invoked.

A further difference between liquid and vapour procedures to 'soak' the samples is the significant development of fissures in the case of liquid suction saturation. Cardoso \& Alonso (2009) describe a stress analysis of expansive marl specimens that helps in understanding the development of cracking. Strong suction gradients result in tensile stresses that are responsible for the observed cracking.

\section{RELATIVE HUMIDITY CYCLING AT MICRO LEVEL}

Additional basic information on the degradation mechanisms is given by SEM + EDS microscopic observations, and by MIP data analysis. A slice $1 \mathrm{~mm}$ thick $(10 \mathrm{~mm} \times 10 \mathrm{~mm}$ sides), carefully cut to avoid breakage, was used for the SEM observations. The experimental procedure relies on two stages (see Pineda, 2012, for additional details). First, SEM photomicrographs were obtained to evaluate the structural arrangement of the undisturbed material. In the second stage, the sample was externally subjected to a fast wetting-drying cycle. Wetting was applied by adding a drop of distilled 
Table 5. Final values of $\varepsilon_{\mathrm{v}}, E, G$ and $\sigma_{\mathrm{t}}$ for samples subjected to Test Series 1

\begin{tabular}{|c|c|c|c|c|c|c|c|c|c|}
\hline$N$ & Specimen & $\mathrm{RH}_{\mathrm{f}}: \%$ & $\varepsilon_{\mathrm{v} \text {-final }}: \%$ & $E: \mathrm{GPa}$ & $E / E_{0}$ & $G: \mathrm{GPa}$ & $G / G_{0}$ & $\sigma_{\text {t-peak }}: \mathrm{kPa}$ & $\sigma_{\mathrm{tp}} / \sigma_{\mathrm{t}-\mathrm{p} 0)}$ \\
\hline $0 \cdot 5$ & 38 mm_S3 & 99 & $-2 \cdot 06$ & $12 \cdot 46$ & $0 \cdot 43$ & - & - & - & - \\
\hline $0 \cdot 5$ & 38 mm_S11 & 99 & $-2 \cdot 65$ & $12 \cdot 18$ & $0 \cdot 42$ & - & - & - & - \\
\hline $0 \cdot 5$ & 38 mm_S4_1 & 99 & $-2 \cdot 54$ & $12 \cdot 86$ & $0 \cdot 41$ & - & - & - & - \\
\hline $0 \cdot 5$ & 50 mm_s4 & 99 & $-2 \cdot 16$ & $25 \cdot 86$ & 0.72 & $9 \cdot 66$ & 0.56 & - & - \\
\hline 1 & 38 mm_S4 & 50 & -0.75 & $12 \cdot 89$ & $0 \cdot 45$ & - & - & - & - \\
\hline 1 & 50 mm_S2 & 50 & $-0 \cdot 92$ & $12 \cdot 13$ & $0 \cdot 36$ & $5 \cdot 04$ & $0 \cdot 32$ & - & - \\
\hline $1 \cdot 5$ & 38 mm_S6 & 99 & $-3 \cdot 38$ & $4 \cdot 95$ & $0 \cdot 17$ & - & - & - & - \\
\hline $1 \cdot 5$ & 50 mm_S1 & 99 & $-2 \cdot 81$ & $19 \cdot 14$ & 0.56 & $9 \cdot 10$ & $0 \cdot 48$ & - & - \\
\hline 2 & 38 mm_S7 & 50 & $-2 \cdot 21$ & $3 \cdot 50$ & $0 \cdot 12$ & - & - & - & - \\
\hline 2 & 38 mm_S3N & 50 & $-1 \cdot 25$ & $4 \cdot 75$ & $0 \cdot 15$ & $2 \cdot 52$ & $0 \cdot 21$ & - & - \\
\hline $2 \cdot 5$ & 38 mm_S4N & 99 & $-2 \cdot 37$ & 3.93 & $0 \cdot 13$ & $2 \cdot 60$ & $0 \cdot 27$ & - & - \\
\hline $2 \cdot 5$ & 38 mm_S5N & 99 & $-2 \cdot 41$ & $3 \cdot 86$ & $0 \cdot 13$ & $2 \cdot 53$ & $0 \cdot 22$ & - & - \\
\hline 4 & 38 mm_S2 & 50 & $-3 \cdot 48$ & 0.995 & 0.035 & - & - & - & - \\
\hline 4 & 38 mm_S5 & 50 & $-3 \cdot 91$ & $1 \cdot 16$ & $0 \cdot 04$ & - & - & - & - \\
\hline 4 & 38 mm_S8 & 50 & $\mathrm{BBH}$ & $\mathrm{BBH}$ & $\mathrm{BBH}$ & - & - & - & - \\
\hline 0 & SBT_1N & 50 & 0 & - & - & - & - & 2949 & 1 \\
\hline 0 & $\mathrm{SBT}_{-} 1$ & 50 & 0 & - & - & - & - & 2751 & 1 \\
\hline $0 \cdot 5$ & $\mathrm{SBT}_{2} 3 \mathrm{~N}$ & 99 & $-2 \cdot 68$ & - & - & - & - & 1100 & $0 \cdot 39$ \\
\hline 1 & SBT_4 & 99 & -0.79 & - & - & - & - & 1300 & $0 \cdot 46$ \\
\hline $1 \cdot 5$ & SBT_2 & 99 & $-3 \cdot 72$ & - & - & - & - & 565 & $0 \cdot 19$ \\
\hline 2 & SBT_2N & 50 & $-1 \cdot 53$ & - & - & - & - & 573 & $0 \cdot 20$ \\
\hline 4 & SBT_4N & 50 & $-3 \cdot 74$ & - & - & - & - & 183 & $0 \cdot 07$ \\
\hline 4 & $\mathrm{SBT}_{-} 3$ & 50 & $-3 \cdot 72$ & - & - & - & - & 346 & $0 \cdot 12$ \\
\hline
\end{tabular}

BBH: samples broken by handling during last drying stage.

Table 6. Final values of $\varepsilon_{\mathrm{v}}, V_{\mathrm{s}}$ and $G$ for specimens subjected to Test Series 2,3 and 4

\begin{tabular}{|c|c|c|c|c|c|c|c|c|c|}
\hline Test series & Specimen & $p-u_{\mathrm{a}}: \mathrm{kPa}$ & RH: \% & $N$ & $\varepsilon_{\mathrm{v}}: \%$ & $V_{\mathrm{s}}: \mathrm{m} / \mathrm{s}$ & $V_{\mathrm{s}} / V_{\mathrm{s} 0}$ & $G: \mathrm{GPa}$ & $G / G_{0}$ \\
\hline $\begin{array}{l}2 \\
3 \\
4\end{array}$ & $\begin{array}{l}50 \text { mm_SN1 } \\
50 \mathrm{~mm} \_S 3 \\
50 \mathrm{~mm} \_S 3 N \\
38 \mathrm{~mm} \_\mathrm{ST} 1\end{array}$ & $\begin{array}{r}50 \\
200 \\
0 \\
0\end{array}$ & $\begin{array}{r}20-99 \\
20-99 \\
50-100 \\
50-100\end{array}$ & $\begin{array}{l}2 \\
2 \\
0 \cdot 5 \\
0 \cdot 5\end{array}$ & $\begin{array}{c}-5 \cdot 30 \\
-0 \cdot 60 \\
- \\
-\end{array}$ & $\begin{array}{r}600 \\
1550 \\
250 \\
382\end{array}$ & $\begin{array}{l}0 \cdot 31 \\
0 \cdot 69 \\
0 \cdot 11 \\
0 \cdot 21\end{array}$ & $\begin{array}{c}0 \cdot 96 \\
6 \cdot 38 \\
- \\
-\end{array}$ & $\begin{array}{c}0 \cdot 10 \\
0 \cdot 47 \\
- \\
-\end{array}$ \\
\hline
\end{tabular}

water during $5 \mathrm{~min}$. Then excess water was carefully removed from the surface of the sample, followed by airdrying at room conditions $(\mathrm{RH} \approx 50 \%)$ for $1 \mathrm{~h}$. Finally, the sample was again placed in the SEM chamber (allowing for equilibrium with the internal environment over $30 \mathrm{~min}$ ). New SEM photomicrographs were taken of the same zone, so that the rock degradation was evaluated by comparing the photomicrographs obtained in the initial and final states. The results are given in Fig. 19. Figs 19(a), 19(b) and 19(c) correspond to the undisturbed state, whereas Figs 19(d), 19(e) and 19(f) show the final state after application of the $\mathrm{RH}$ cycle described above. The undisturbed stage may be described as a dense clayey matrix (mainly illite and kaolinite) hosting minerals of large size (dolomite, calcite, quartz and large illite crystals). Small pre-existing fissures were also detected. Comparison between the initial and final states shows significant structural changes induced by application of the rapid $\mathrm{RH}$ cycle. Pre-existing fissures evolved in thickness and length, as observed in Figs 19(d) and 19(e). New fissures with a thickness close to $30 \mu \mathrm{m}$ were observed in different zones of the specimen. However, the most interesting result was detected at higher magnification $(\times 5000)$ (compare Figs 19(c) and 19(f)). It can be seen that fissuring took place mainly at the interfaces between the large-size minerals and the clayey matrix (grain boundaries indicated by arrows in Fig. 19(f)). Some fissuring of the clayey matrix was also observed. Enhanced fissuring at grain boundaries was associated with non-uniform deformations developed between the stiffer, large-size minerals (mainly non-active) and the softer clayey matrix. Thus microfissuring seems to be the main degradation mechanism taking place in Lilla claystone during RH cycling.

Qualitative SEM results were complemented by MIP tests, and also by the Barrett, Joyner and Halenda (BJH) method for nitrogen desorption. The freeze-drying process (Delage et al., 1982) was applied to all specimens before testing. Fig. 20(a) shows the pore-size density functions for specimens at different degradation states. Only specimens exposed to vapour (no liquid water) are shown. In all cases, the dominant pore-size diameter was located at the ultramicroporosity zone, which is associated with the very dense clayey matrix identified in SEM observations. The application of RH cycles increased the dominant pore-size diameter from around $3.5 \mathrm{~nm}$ to $9 \mathrm{~nm}$. It is also observed that new peaks develop at the macroporosity zone $(5-40 \mu \mathrm{m})$, which could be associated with microfissuring.

Exposing samples to liquid water (Fig. 20(b)) results in a substantial increase in microfissuring in the 20-40 $\mu \mathrm{m}$ range. Now, the development of a second dominant mode is very clear. This is similar to microstructural observations reported by Montes et al. (2004), and it supports the recent proposal by Arson \& Pereira (2012) in which a pore-size distribution model for cracked samples, accounting for the generation of a large-size mode of pore-size distribution, is proposed. The large dominant mode is similar in magnitude to the thickness of fissures detected by SEM analysis (see Fig. 19(f)) where a fast RH cycle, using liquid water, was applied. It confirms that the main degradation mechanism - during $\mathrm{RH}$ 


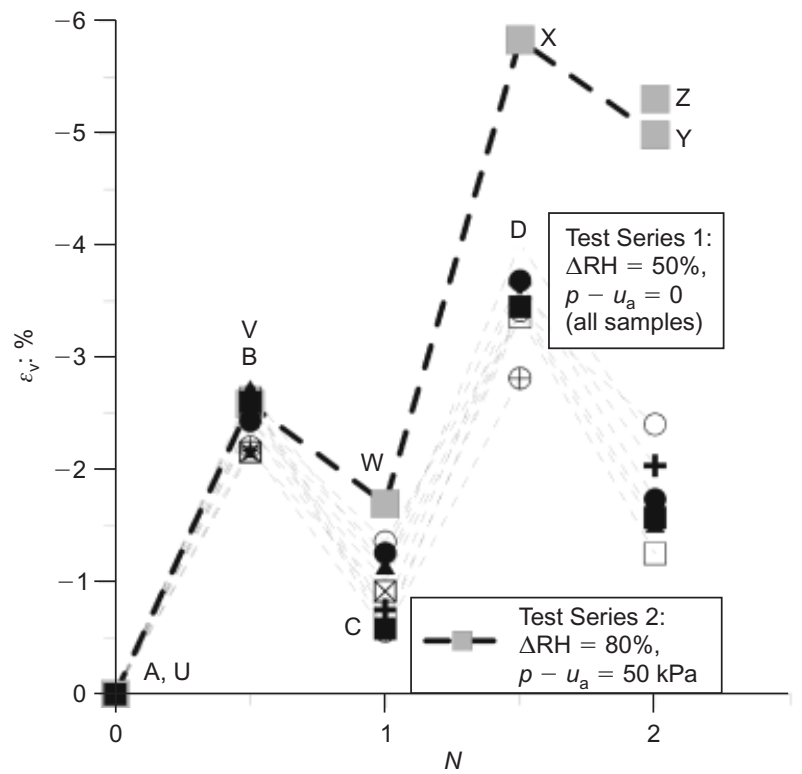

(a)

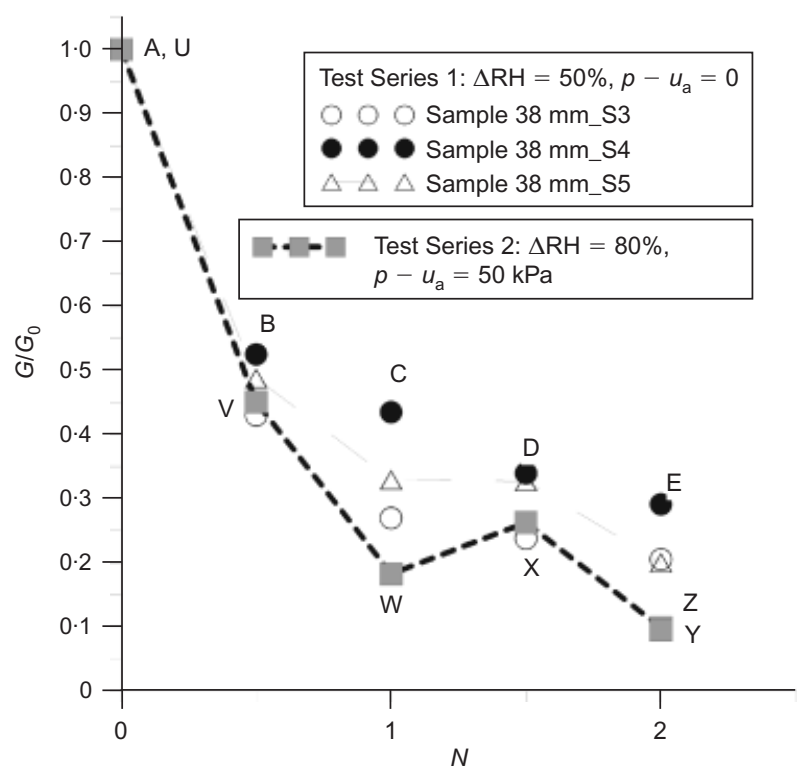

(b)

Fig. 15. Influence of $\Delta R H$ on (a) volume change and (b) rock stiffness during RH cycling

cycling - is due to a non-homogeneous volume change at the micro level, which induces microfissuring. In addition, the creation of the new pore mode was in agreement with the macroscopic fissuring observed in some specimens during drying. The new pore space created by fissuring decreased the rock stiffness, and created preferential paths for gas/liquid flow. Triaxial tests reported by Pineda (2012) provide experimental evidence in this regard.

\section{DEGRADATION LAW FOR LILLA CLAYSTONE}

Experimental results presented above have shown the strong dependence of the degradation process of argillaceous rocks on changes of $\mathrm{RH}$ not only at the macro scale but also at the micro scale. $\mathrm{RH}$ cycling induced a progressive decrease of the mechanical properties of the rock (rock stiffness and tensile strength). It was accompanied by a progressive volumetric swelling. At the end of the complete $\mathrm{RH}$ cycle (wetting and drying) irreversible volumetric strains were recorded (see Figs 3, 4, 10, 12 and 15). Damage will

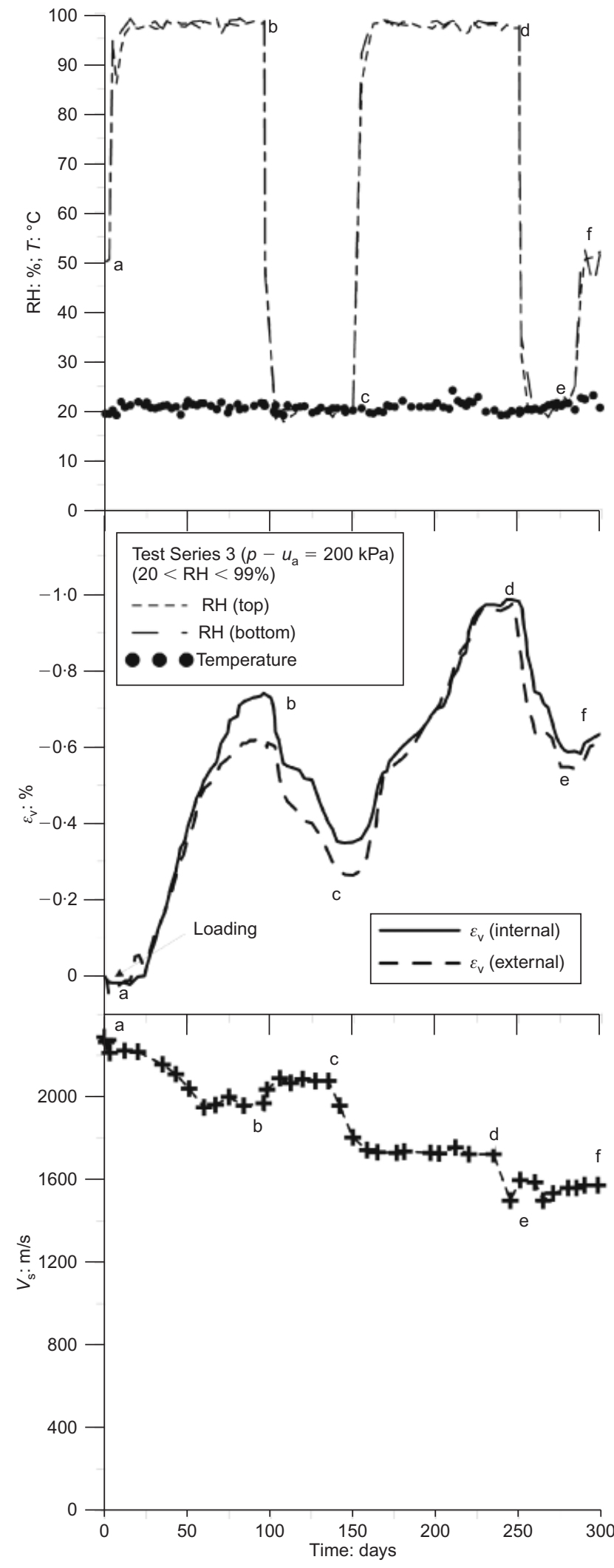

Fig. 16. Evolution of volumetric strain and shear wave velocity during Test Series $3\left(\Delta \mathrm{RH} \approx 80 \%, p-u_{\mathrm{a}}=200 \mathrm{kPa}, N=2\right)$

be related to the irreversible volumetric strain increment, which is calculated by adding the contributions of swelling and shrinkage effects as

$$
\begin{aligned}
\Delta \varepsilon_{\mathrm{V}}^{\text {damage }_{(i)}} & =\left|\Delta \varepsilon_{\mathrm{V}}^{\text {irreversible }_{(i)}}\right| \\
& =\left|\Delta \varepsilon_{\mathrm{V}}^{\mathrm{W}_{(i)}}\right|-\left|\Delta \varepsilon_{\mathrm{V}}^{\mathrm{D}_{(i)}}\right|
\end{aligned}
$$




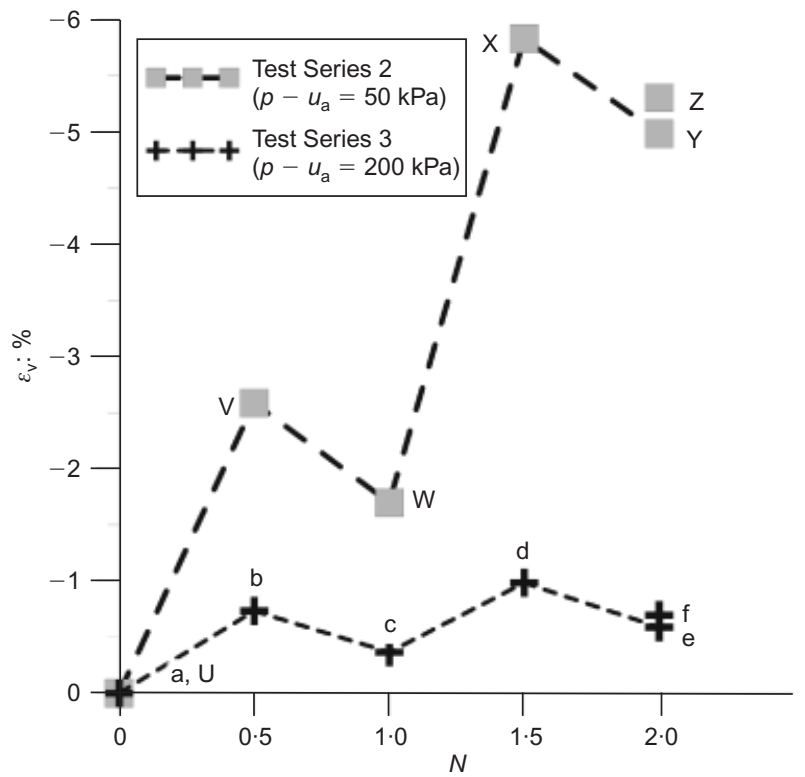

(a)

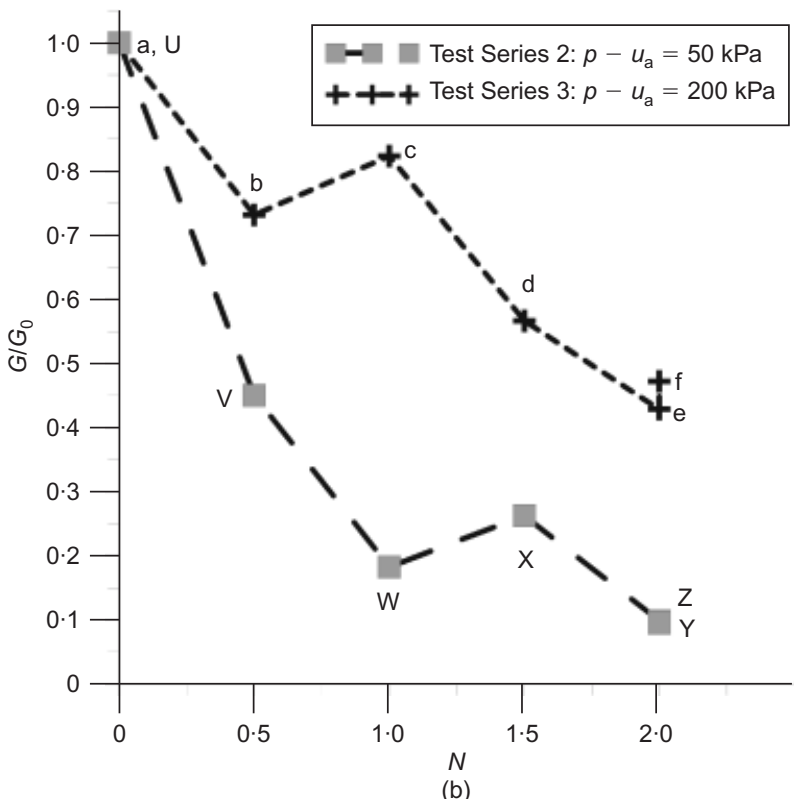

Fig. 17. Influence of $p-u_{\mathrm{a}}$ on (a) volume change and (b) rock stiffness during RH cycling

where $i$ refers to the specific cycle analysed.

Figure 21 compares the accumulated damage volumetric strains, $\varepsilon_{\mathrm{v}}^{\text {damage }}$, obtained in Test Series 1,2 and 3 as a function of the number of $\mathrm{RH}$ cycles, $N$. The results combine different effects: the effect of confining stress $\left(p-u_{\mathrm{a}}\right)$ and the range of suction change $(\Delta \mathrm{RH})$. In Test Series 1 (the lowest confinement, and a $50 \%$ variation in $\mathrm{RH})$ a linear trend of $\varepsilon_{\mathrm{v}}^{\text {damage }}$ with the number of cycles is shown in the results. $\varepsilon_{\mathrm{v}}^{\text {damage }}$ increased in Test Series 2, when only two RH cycles of higher amplitude were applied at a somewhat higher confining stress $(50 \mathrm{kPa})$. Increasing the confining stress to $200 \mathrm{kPa}$ in Test Series 3 resulted in a very significant decrease in swelling.

However, the effect of these factors on the evolution of the mechanical properties of the rock may be unified if the irreversible volumetric strain is taken as the main controlling variable. This is shown in Fig. 22, which compares the evolution of the normalised elastic moduli and the tensile strength, measured in Test Series 1, 2 and 3, with the corresponding volumetric damage strains induced in each

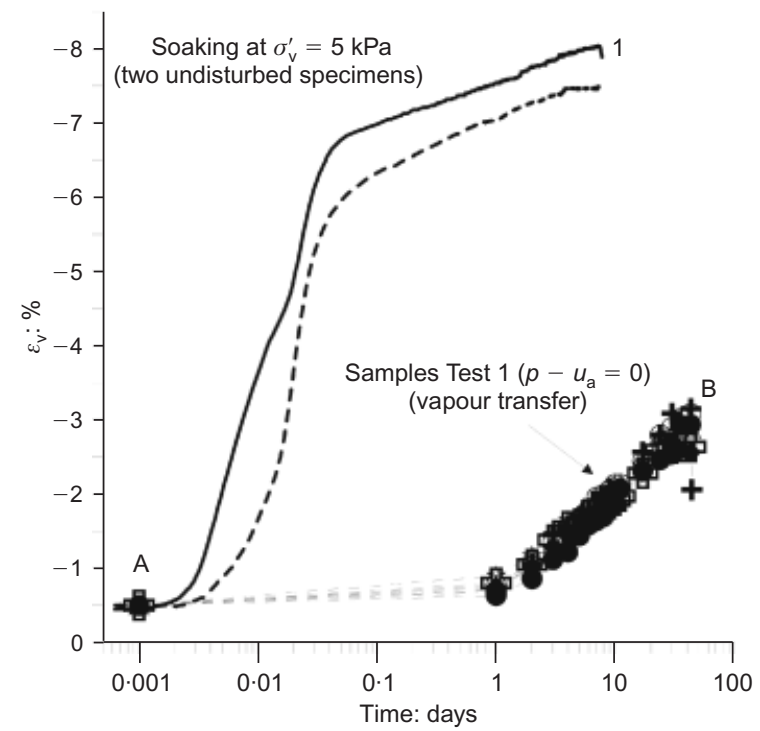

(a)

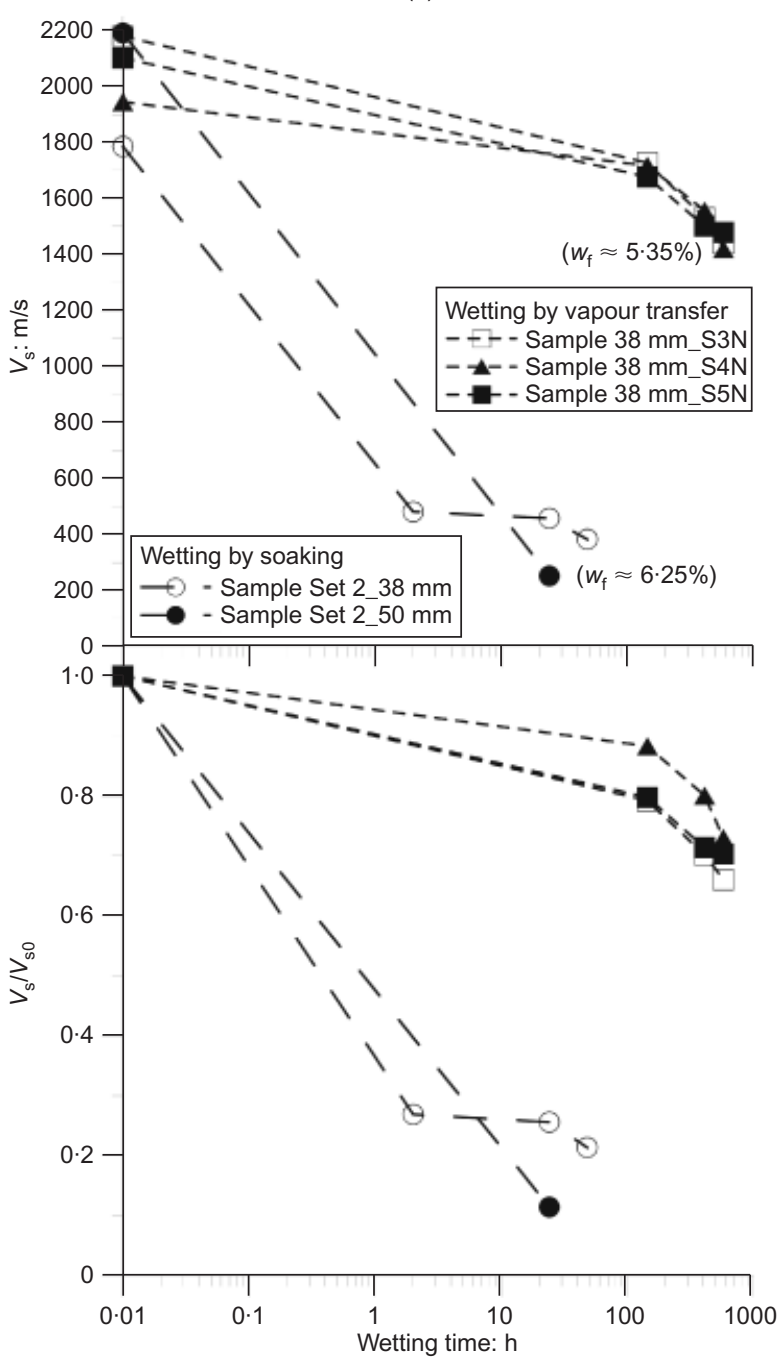

(b)

Fig. 18. Influence of fluid used during wetting paths (Test 4): (a) volumetric swelling; (b) shear wave velocity

case. The three properties follow a unique degradation pattern, irrespective of the specific combination of $N, \Delta \mathrm{RH}$ and $p-u_{\mathrm{a}}$. It follows that the degradation process could be defined by a unique expression relating the normalised $E, G$ and $\sigma_{\mathrm{t}}$ with $\varepsilon_{\mathrm{v}}^{\text {damage }}$. 


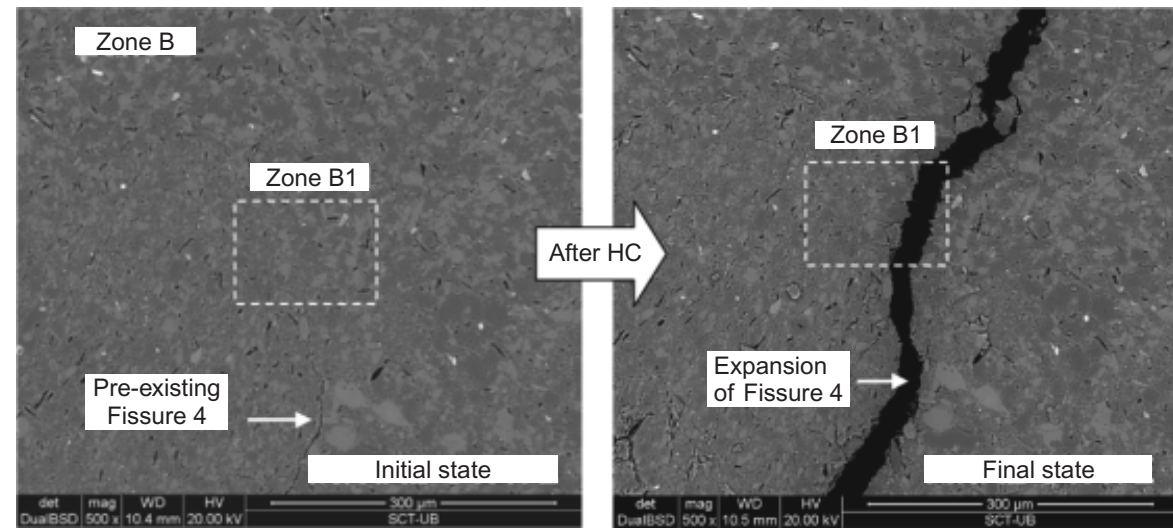

(a)

(d)

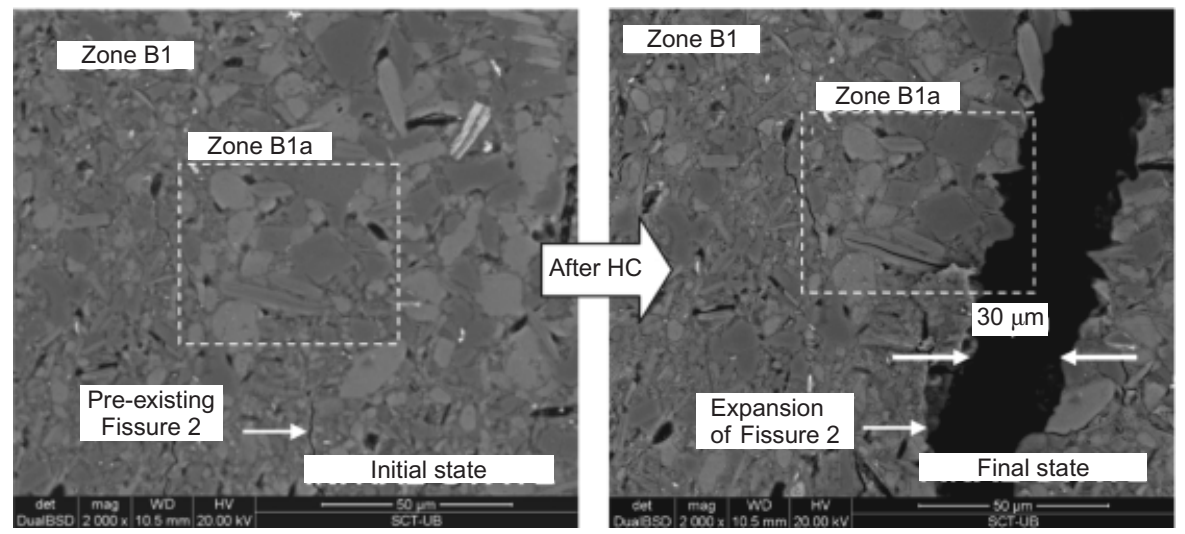

(b)

(e)

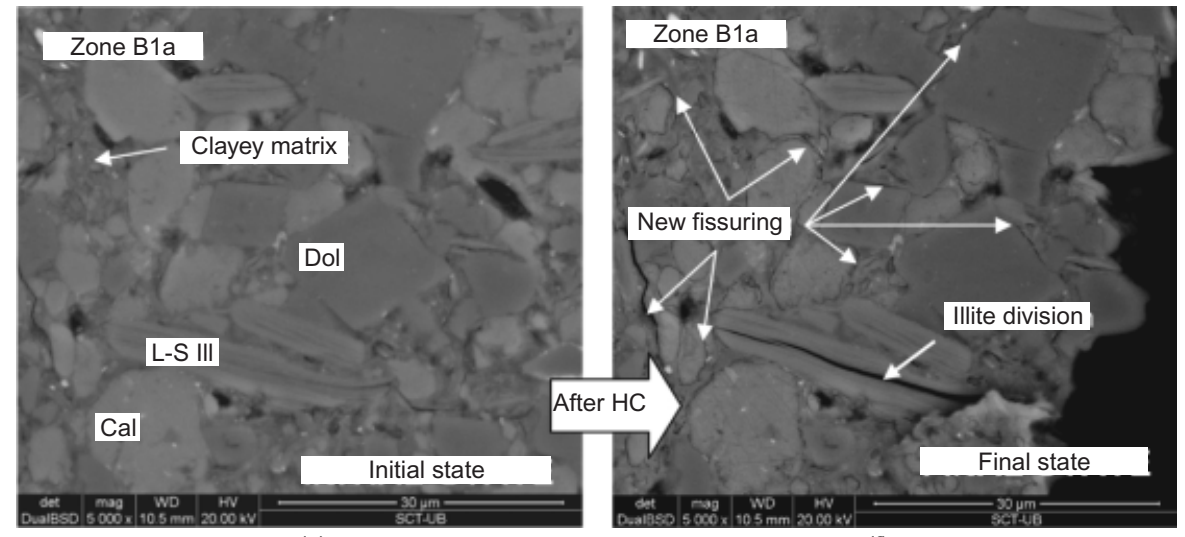

(c)

(f)

Fig. 19. SEM photomicrographs: (a), (b), (c) initial state; (d), (e), (f) degraded state (microfissuring)

Consider the simple one-dimensional degradation law as proposed, for instance, in Schön (2006)

$$
S=S_{0}(1-D)
$$

where $S$ and $S_{0}$ are the current and initial values of a given property, and $D$ is a damage parameter ranging between 0 (undisturbed state) and 1 (fully disturbed state).

The experimental results shown in Fig. 22 suggest that the rate of damage change is proportional to the current state according to

$$
-\frac{\mathrm{d}(1-D)}{\mathrm{d} \varepsilon_{\mathrm{v}}^{\text {damage }}} \propto(1-D)
$$

Integration of equation (6) leads to

$$
1-D=\left(1-D_{0}\right) \exp \left(-\chi\left|\varepsilon_{\mathrm{v}}^{\text {damage }}\right|\right)
$$

Equation (7) predicts a complete degradation of rock properties if the plastic volumetric strain increases. The parameter $\chi$ controls the rate of degradation. However, the results in Fig. 22 indicate that a residual value of any of the properties analysed may be maintained at high values of $\varepsilon_{\mathrm{v}}^{\mathrm{damage}}$. Equation (7) was generalised to

$$
1-D=\left[\left(1-D_{0}\right)-r\right] \exp \left(-\chi\left|\varepsilon_{\mathrm{v}}^{\text {damage }}\right|\right)+r
$$

to make it more flexible. In terms of the three variables analysed

$$
\begin{aligned}
& E=E_{0}\left\{\left[\left(1-D_{0}\right)-r\right] \exp \left(-\chi \varepsilon_{\mathrm{v}}^{\text {damage }}\right)+r\right\} \\
& G=G_{0}\left\{\left[\left(1-D_{0}\right)-r\right] \exp \left(-\chi \varepsilon_{\mathrm{v}}^{\text {damage }}\right)+r\right\} \\
& \sigma_{\mathrm{t}}=\sigma_{\mathrm{t} 0}\left\{\left[\left(1-D_{0}\right)-r\right] \exp \left(-\chi \varepsilon_{\mathrm{v}}^{\text {damage }}\right)+r\right\}
\end{aligned}
$$




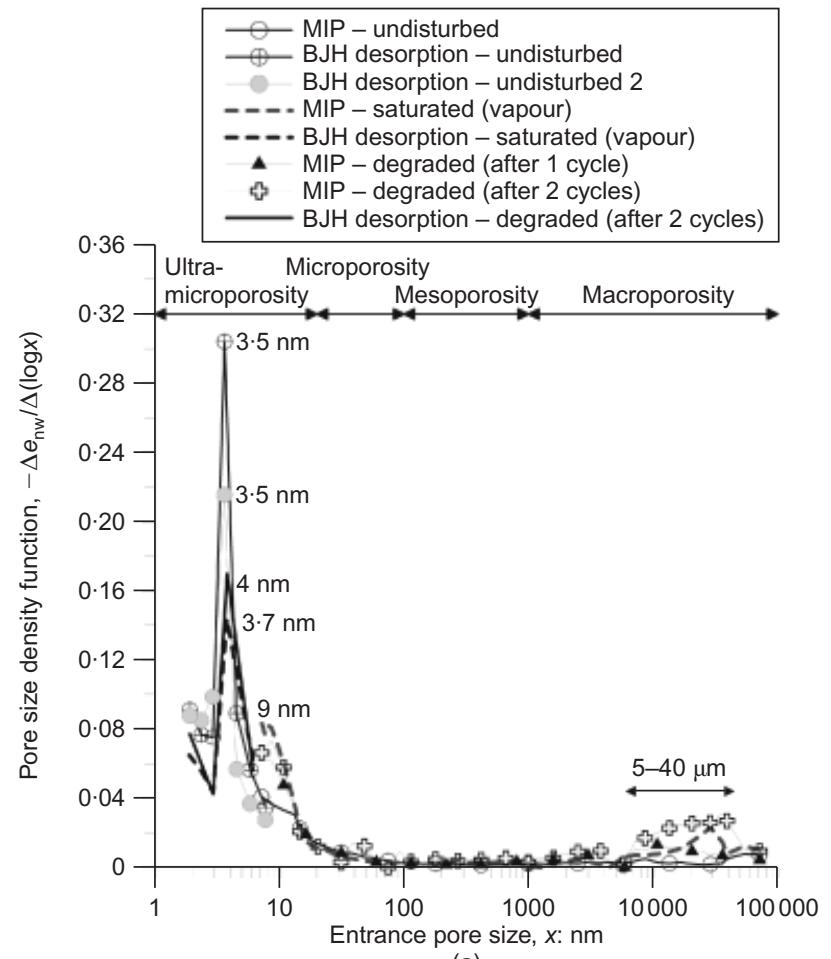

(a)

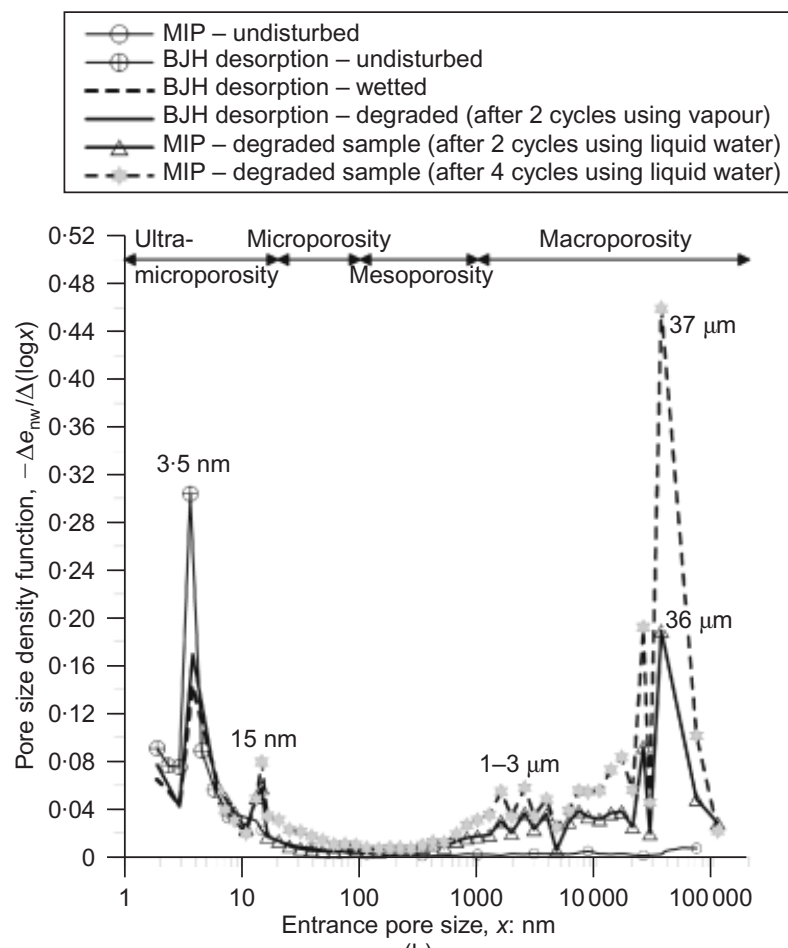

(b)

Fig. 20. Evolution of pore size modes during degradation: (a) vapour transfer; (b) vapour and liquid transfer

The proposed degradation law has been plotted in Fig. 22 as a continuous line for $D_{0}=0, \chi=1 \cdot 3$ and $r=0.06$. Good agreement is observed with the experimental data. Similar laws have been proposed by other authors (e.g. Carol et al., 2001). The singularity of the results presented in this paper is that a unique law seems to describe the damage of volumetric and shear stiffness as well as tensile strength. This result simplifies the derivation of a general degradation law if only results for a given property, say rock stiffness, are available.

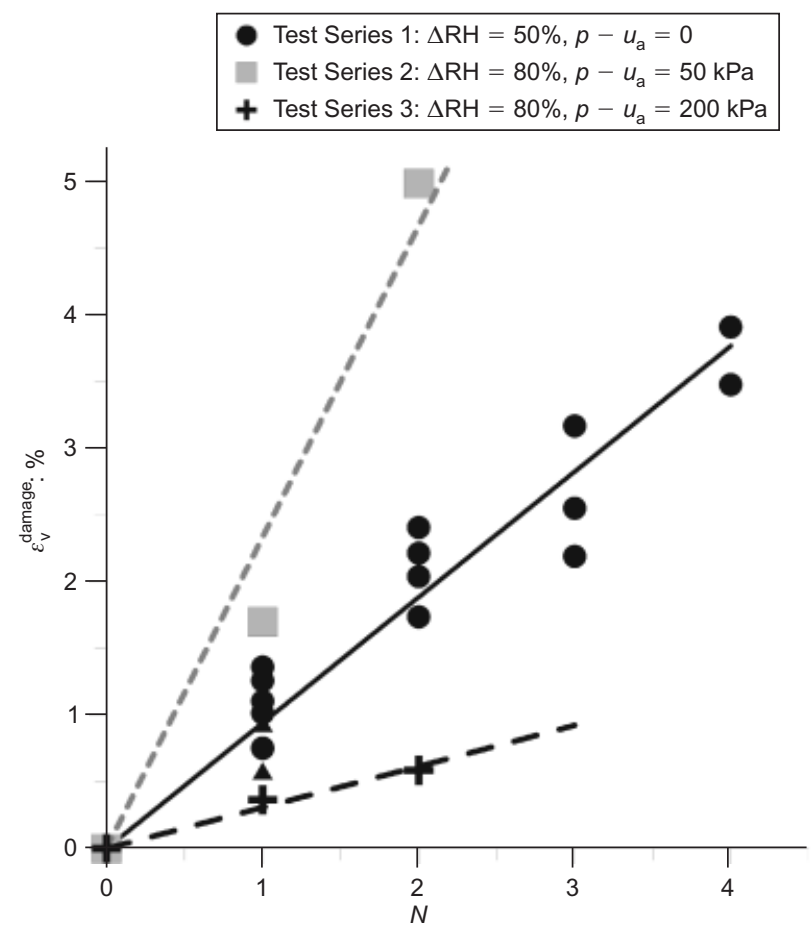

Fig. 21. Variation of $\varepsilon_{\mathrm{v}}^{\text {damage }}$ with $N$ during Test Series 1,2 and 3

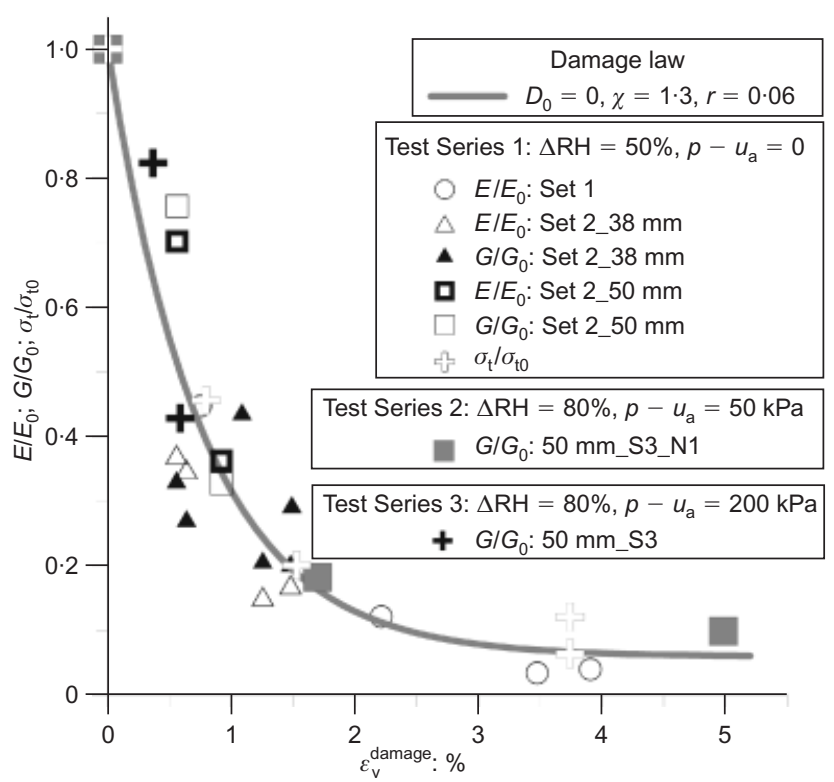

Fig. 22. Degradation of rock stiffness and tensile strength with $\varepsilon_{\mathrm{v}}^{\text {damage }}$, and proposed damage law

\section{CONCLUDING REMARKS}

This paper has examined the progressive degradation of the mechanical properties of clayey rocks due to cyclic changes in RH. This is a common situation in open excavations and tunnelling. Lilla claystone, a low-porosity argillaceous rock from the Tertiary age, was used for this purpose.

The four main aspects experimentally investigated in the paper were

(a) the influence of the number of RH cycles

(b) the amplitude of the cycles

(c) the stress state

(d) the comparison between liquid water and vapour when inducing degradation.

The rock response was observed not only at the macroscopic 
scale by means of long-term RH cycling tests, but also at a microscopic scale. The application of consecutive RH cycles induced cumulative and irreversible volumetric swelling of the rock. It was accompanied, in most cases, by a progressive fissuring of the rock. Irreversible swelling increased with enhancement of the amplitude of the RH change. However, it reduced with an increase of confining stress level. This irreversible behaviour was accelerated when liquid water was used during the wetting paths, ensuring full saturation. From a microstructural viewpoint, SEM images have shown that the degradation pattern of Lilla claystone is associated mainly with fissuring, especially at the interfaces of the clayey matrix with detrital, non-active minerals. Fissuring also implied the emergence of a new dominant pore size observed in MIP tests. Visual inspection at the laboratory scale also confirmed the creation of a fissuring pattern in specimens. Samples exhibited a progressive reduction of rock stiffness and tensile strength with the application of hydraulic cycles. Degradation was more significant when the range of $\mathrm{RH}$ cycles applied was increased. A unique damage law, expressed in terms of the accumulated volumetric irreversible strain, has been proposed to represent the progressive loss in shear and volumetric stiffness and tensile strength. Good agreement was observed between experimental data and the proposed damage law, which could be included in constitutive models for soft rocks.

\section{ACKNOWLEDGEMENTS}

The first author acknowledges the financial support provided by the ALBAN PROGRAMME grants (2004/2007) from the European Commission, EU Programme of High Level Scholarships for Latin America, id number E04D027285CO.

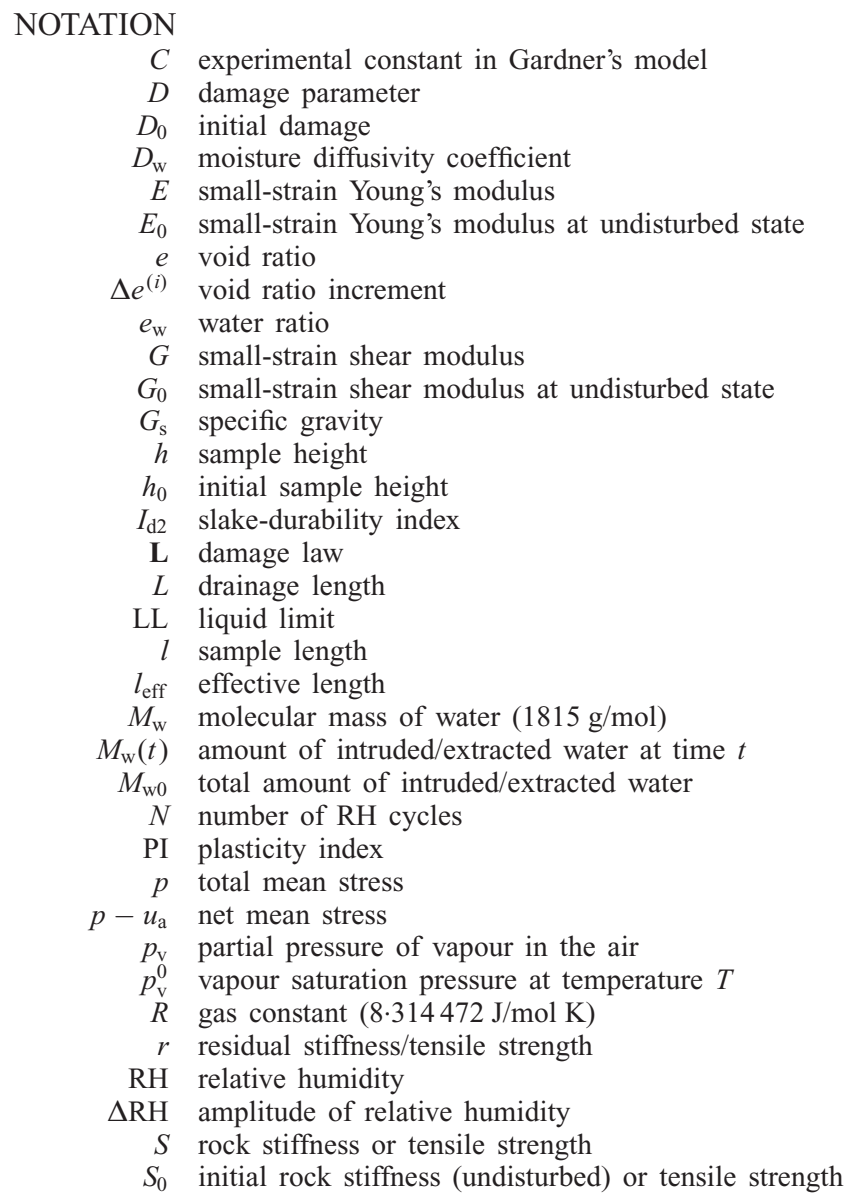

$S_{\mathrm{r}} \quad$ degree of saturation

$T$ temperature

$T_{\mathrm{v}}$ time factor

$t_{\mathrm{p}}$ travel time of longitudinal wave

$t_{\mathrm{s}}$ travel time of shear wave

$t_{95}$ time required to reach $95 \%$ of water inflow/outflow

$u_{\mathrm{a}}$ atmospheric pressure

$V_{\mathrm{L}} \quad$ longitudinal velocity

$V_{\mathrm{s}}$ shear wave velocity

$w$ gravimetric water content

$\varepsilon_{\mathrm{a}}$ axial strain

$\varepsilon_{\mathrm{a}} / \varepsilon_{\mathrm{r}}$ strain ratio

$\varepsilon_{\mathrm{r}}$ radial strain

$\varepsilon_{\mathrm{V}} \quad$ volumetric strain

$\Delta \varepsilon_{\mathrm{v}}^{\mathrm{D}(i)} \quad$ volumetric strain increment during drying

$\varepsilon_{\mathrm{V}}^{\text {damage }}$ damage volumetric strain

$\Delta \varepsilon_{\mathrm{v}}^{\text {damage }(i)}$ damage volumetric strain increment

$\Delta \varepsilon_{\mathrm{v}}^{\text {irreversible }(i)}$ irreversible volumetric strain increment (\%)

$\Delta \varepsilon_{\mathrm{v}}^{\mathrm{W}(i)} \quad$ Volumetric strain increment during wetting $(\%)$

$\rho_{\mathrm{d}}$ dry density

$\rho_{\mathrm{s}} \quad$ density of solids

$\rho_{\mathrm{t}} \quad$ total density

$\rho_{\mathrm{w}}$ density of pure water $\left(0.998 \mathrm{Mg} / \mathrm{m}^{3}\right.$ at $\left.20^{\circ} \mathrm{C}\right)$

$\sigma_{\mathrm{t}} \quad$ tensile strength

$\sigma_{\text {t-peak }}$ peak tensile strength

$\sigma_{\mathrm{t}-\text { peak }(0)}$ peak tensile strength at undisturbed state

$\phi$ sample diameter

$\chi$ degradation rate

$\psi$ total suction (water potential)

\section{REFERENCES}

Alonso, E. E. \& Alcoverro, J. (2004). Swelling and degradation of argillaceous rocks. In Proceedings of the 3rd international conference on unsaturated soils (eds J. F. T. Juca, T. M. P. de Campos and F. A. M. Marinho), pp. 951-972. Lisse, the Netherlands: Swets \& Zeitlinger.

Alonso, E. E., Berdugo, I. R., Tarragó, D. \& Ramon, A. (2007). Tunnelling in sulphate claystones. Invited lecture. Proceedings of the 14th European conference on soil mechanics and geotechnical engineering, Madrid, Spain, vol. 1, pp. 103-122.

Alonso, E. E., Pineda, J. A. \& Cardoso, R. (2010). Degradation of marls: two cases studies from the Iberia Peninsula. In Weathering as a predisposing factor to slope movements (eds D. Calcaterra and M. Parise), Engineering Geology Special Publication 23, pp. 47-75. London, UK: Geological Society.

Alonso, E. E., Berdugo, I. R. \& Ramon, A. (2013). Extreme expansive phenomena in anhydritic-gypsiferous claystone: the case of Lilla tunnel. Géotechnique 63, No. 7, 584-612, http:// dx.doi.org/10.1680/geot.12.P.143.

Arroyo, M., Pineda, J. A. \& Romero, E. (2010). Shear wave measurements using bender elements in argillaceous rocks. ASTM Geotech. Test. J. 33, No. 6, 1-11.

Arson, C. \& Pereira, J.-M. (2012). Influence of damage on pore size distribution and permeability of rocks. Int. J. Numer. Analyt. Methods Geomech. 37, No. 8, 810-831.

ASTM (2008). ASTM D4644-08: Standard test method for slake durability of shales and similar weak rocks. West Conshohocken, PA, USA: ASTM International.

Berdugo, I. R. (2007). Tunnelling in sulphate-bearing rocks: Expansive phenomena. $\mathrm{PhD}$ thesis, Universitat Politècnica de Catalunya, Barcelona, Spain.

Bjerrum, L. (1967). Progressive failure in slopes of overconsolidated plastic clay and clay shales. J. Soil Mech. Found. Div., ASCE 93, No. 5, 3-49.

Blatz, J. A., Cui, Y.-J. \& Oldecop, L. (2008). Vapour equilibrium and osmotic technique for suction control. Geotech. Geol. Engng 26, No. 6, 661-673.

Botts, M. E. (1986). The effects of slaking on the engineering behaviour of clay shales. PhD thesis, University of Colorado, Boulder, CO, USA.

Cafaro, F. \& Cotecchia, F. (2001). Structure degradation and changes in the mechanical behaviour of a stiff clay due to weathering. Géotechnique 51, No. 5, 441-453, http://dx.doi.org/ 10.1680/geot.2001.51.5.441. 
Cardoso, R. \& Alonso, E. E. (2009). Degradation of compacted marls: a microstructural investigation. Soils Found. 49, No. 3, 315-327.

Cardoso, R., Romero, E., Lima, A. \& Ferrari, A. (2007). A comparative study of soil suction measurement using two different high-range psychrometers. In Proceedings of the 2nd international conference on mechanics of unsaturated soils (ed. T. Schanz), pp. 79-94. Berlin, Germany: Springer-Verlag.

Cardoso, R., Della Vecchia, G., Jommi, C. \& Romero, E. (2010). Water retention curve for evolving marl under suction cycles. In Proceedings of the 5th international unsaturated conference on unsaturated soils (eds E. Alonso and A. Gens), pp. 1451-1457. London, UK: Taylor \& Francis.

Cardoso, R., Maranha des Neves, E. \& Alonso, E. E. (2012). Experimental behaviour of compacted marls. Géotechnique $\mathbf{6 2}$ No. 11, 999-1012, http://dx.doi.org/10.1680/geot.10.P.093.

Carol, I., Rizzi, E. \& William, K. (2001). On the formulation of anisotropic elastic degradation. I. Theory based on a pseudologarithmic damage tensor rate. Int. J. Solids Struct. 38, No. 4, 491-518.

Chandler, R. J. (1969). The effect of weathering on the shear strength properties of Keuper marl. Géotechnique 19, No. 3, 321-334, http://dx.doi.org/10.1680/geot.1969.19.3.321.

Chandler, R. J. (1972). Lias clay: weathering processes and their effect on shear strength. Géotechnique 22, No. 3, 403-431, http://dx.doi.org/10.1680/geot.1972.22.3.403.

Charpentier, D., Tessier, D. \& Cathelineau, M. (2003). Shale microstructure evolution due to tunnel excavation after 100 years and impact of tectonic paleo-fracturing. Case of Tournemire, France. Engng Geol. 70, No. 1-2, 55-69.

Coussy, O. (1995). Mechanics of porous continua. Chichester, UK: Wiley.

Cripps, J. C. \& Taylor, R. K. (1981). The engineering properties of mudrocks. Q. J. Engng Geol. Hydrogeol. 14, No. 4, 325-346.

Delage, P., Tessier, D. \& Audiguier, M. (1982). Use of the Cryoscan apparatus for observation of freeze-fractured planes of a sensitive Quebec clay in scanning electron microscopy. Can. Geotech, J. 19, No. 1, 111-114.

Delage, P., Howat, M. D. \& Cui, Y. J. (1998). The relationship between suction and swelling properties in a heavily compacted unsaturated clay. Engng Geol. 50, No. 1-2, 31-48.

Delage, P., Romero, E. \& Tarantino, A. (2008). Recent developments in the techniques of controlling and measuring suction in unsaturated soils. In Proceedings of the 1st European conference on unsaturated soils (ed. D. Toll), pp. 33-52. Abingdon, UK: Taylor \& Francis Group.

Fabre, G. \& Pellet, F. (2006). Creep and time-dependent damage in argillaceous rocks. Int. J. Rock Mech. Mining Sci. 43, No. 6, 950-960.

Gardner, W. R. (1956). Calculation of capillary conductivity from pressure plate flow data. Soil Sci. Soc. Am. Proc. 20, No. 3, 317-320.

Gasc-Barbier, M. \& Tessier, D. (2007). Structural modifications of a hard deep clayey rock due to hygro-mechanical solicitations. Int. J. Geomech. 7, No. 3, 227-235.

Gens, A. (2010). Soil-environment interactions in geotechnical engineering. Géotechnique 60, No. 1, 3-74, http://dx.doi.org/ 10.1680/geot.9.P.109.

Gens, A. (2013). On the hydromechanical behaviour of argillaceous hard soils - weak rocks. Proceedings of the 15th European conference on soil mechanics and geotechnical engineering (eds A. Anagnostopoulos, M. Pachakis and C. Tsatsanifos), pp. 71118. Amsterdam, the Netherlands: IOS Press.

Gens, A., Vaunat, J., Garitte, B. \& Wileveau, Y. (2007). In situ behaviour of a stiff layered clay subject to thermal loading: observations and interpretation. Géotechnique 57, No. 2, 207228, http://dx.doi.org/10.1680/geot.2007.57.2.207.

ISRM (1978). Suggested methods for determining tensile strength of rock materials. Int. J. Rock Mech. Min. Sci. Geomech. Abstr. 15, No. 3, 99-103.

Marques, E. A. G., Vargas, E. A. \& Antunes, F. S. (2005). A study of the durability of some shales, mudrocks and siltstones from Brazil. Geotech. Geol. Engng 23, No. 3, 321-348.

Montes, H. R., Duplay, J., Martinez, L., Escoffier, S. \& Rousset, D. (2004). Structural modifications of Callovo-Oxfordian argillite under hydration/dehydration conditions. Appl. Clay Sci. 25, No. 3-4, 187-194.

Olivier, H. J. (1979). Some aspects of the influence of mineralogy and moisture redistribution on the weathering behaviour of mudrocks. Proceedings of the 4th congress of the International Society for Rock Mechanics, Montreux, Switzerland, pp. 467-474.

Pejón, O. J. \& Zuquette, L. V. (2002). Analysis of cyclic swelling of mudrocks. Engng Geol. 67, No. 1-2, 97-108.

Picarelli, L. \& Di Maio, C. (2010). Deterioration processes of hard clays and clay shales. In Weathering as a predisposing factor to slope movements (eds D. Calcaterra and M. Parise), Engineering Geology Special Publication 23, pp. 15-32. London, UK: Geological Society.

Picarelli, L. \& Urciuoli, G. (1993). Effetti dell'erosione in argillite di alta plasticità. Riv. Ital. Geotec. 1, 29-47.

Pineda, J. A. (2012). Swelling and degradation of argillaceous rocks induced by relative humidity effects: An experimental study. PhD thesis, Universitat Politècnica de Catalunya, Barcelona, Spain.

Pineda, J. A. \& Romero, E. (2013). Effects of relative humidity cycling on the hydromechanical properties of two clayey rocks from the North-East Spain. In Proceedings of the 1st PanAmerican conference in unsaturated soils (eds Caicedo, Murillo, Hoyos, Colmenares and Berdugo), pp. 341-346. London, UK: CRS Press, Taylor \& Francis Group.

Rejeb, A. \& Cabrera, J. (2006). Time-dependent evolution of the excavation damaged zone in the argillaceous Tournemire site (France). Proceedings of the 2nd international conference on coupled T-H-M-C processes in geosystems and engineering (GeoProc 2006), Nanjing, China.

Romero, E., Senger, R., Marschall, P. \& Gómez, R. (2012). Air tests on low-permeability claystone formations: experimental results and simulations. In Multiphysical testing of soils and shales (eds L. Laloui and A. Ferrari), pp. 68-83. Berlin, Germany: Springer-Verlag.

Schön, J. H. (2006). Physical properties of rocks: Fundamentals and principles of petrophysics. Amsterdam, the Netherlands: Elsevier.

Valès, F., Nguyen Minh, D., Gharbi, H. \& Rejeb, A. (2004). Experimental study of the influence of the degree of saturation on physical and mechanical properties in Tournemire shale (France). Appl. Clay Sci. 26, No. 1-4, 197-207.

Van Eeckhout, E. M. (1976). The mechanisms of strength reduction due to moisture in coal mine shales. Int. J. of Rock Mech. Min. Sci. 13, No. 1, 61-67.

Vaughan, P. (1997). Engineering behaviour of weak rocks: some answers and some questions. Proceedings of the 3rd international symposium on geotechnical engineering of hard soils-soft rocks, pp. 1741-1765. Rotterdam, the Netherlands: Balkema.

Vicol, T. (1990). Comportement hydraulique et mecànique d'un solfin non saturé: Application à la modèlisation. $\mathrm{PhD}$ thesis, Ecole Nationale des Ponts et Chaussées, Paris, France (in French).

Viggiani, G. \& Atkinson, J. H. (1995). Interpretation of bender element test. Géotechnique 45, No. 1, 149-154, http:// dx.doi.org/10.1680/geot.1995.45.1.149.

Wong, R. C. K. (1998). Swelling and softening behaviour of La Biche shale. Can. Geotech. J. 35, No. 2, 206-221.

Youn, H. \& Tonon, F. (2010). Effects of air-drying duration on the engineering properties of four clay-bearing rocks in Texas. Engng Geol. 115, No. 1, 58-67. 